\title{
Crisis, Policy Discourse, and Major Policy Change: Exploring the Role of Subsystem Polarization in Nuclear Energy Policymaking
}

\author{
Adrian Rinscheid ${ }^{\mathrm{A}}$
}

\begin{abstract}
Why do policy responses to one and the same event often vary so markedly between different jurisdictions? This contribution sheds light on conditions and processes that link crises to policy change or policy stability. Drawing on public policy theories and accounts from crisis management, the type of policy subsystem that is hit by a crisis is theorized to be a decisive factor when it comes to explaining variation in crisis-induced policy reactions. The theoretical arguments are explored based on a comparative case study of Fukushima's differential impact on nuclear power policymaking in Japan and Germany. In order to systematically analyze interaction patterns of policy elites, the study capitalizes on recent methodological advances and applies a method called discourse network analysis. The analysis yields topographies of policy discourses around the Fukushima crisis in both countries and shows that crises can trigger major policy shifts when "anchors" for policy change-i.e., alternative policy ideas and proposals put forward by a minority coalitionare readily available. If a pre-crisis subsystem is unitary, on the other hand, the pressure on incumbents is rather low and policy shifts are prevented from going beyond mere incremental adjustments..
\end{abstract}

Keywords: policy change, policy stability, nuclear power policy, discourse network analysis, polarization, unitary subsystem, adversarial subsystem, policy networks, Japan, Germany

\section{Introduction}

1 mpirical experience shows that crises are frequent triggers of policy activism, and various theoretical perspectives on public policymaking acknowledge that they play an important role when it comes to explaining major policy shifts (Birkland 2006; Boin, 't Hart, and McConnell 2009; Jenkins-Smith et al. 2014; Kingdon 2010). While this may come as little surprise, a more interesting issue relates to the question of "why some crises result in major policy change while others do not" (Nohrstedt 2008, 258). Whereas large policy shifts are in some cases initiated even by relatively small events (Pierson 2000), large-scale exog-

\footnotetext{
${ }^{\text {A }}$ University of St. Gallen, Switzerland
} 
enous shocks, a concept close to that of crisis, sometimes have no imprint on policymaking at all (Birkland 2006; Pollack and Shaffer 2009). Going one step further, the variation in policy responses among different jurisdictions toward one and the same event can be regarded as even more puzzling.

A fully fledged theory for explaining the link between crisis and policy change, however, has not yet been developed, and approaches differ according to how they conceptualize crises and how they relate them to policy outputs. Accordingly, Nohrstedt and Weible $(2010,3)$ note that "differences in crisis impacts [...] call for more careful theorizing regarding the role and impact of crises in public policymaking". In order to better understand the conditions that are necessary for policy change to occur after crises, this contribution links theoretical propositions from the policy process literature with social network analysis. Proceeding from Anderson's $(1978,23)$ observation that the "deliberation of public policy takes place within a realm of discourse", and grounded in the perspective that a societal problem exists mainly "in terms of how it is defined and conceived in a society" (Blumer 1971, 300), the study also gains some inspiration from social constructivism. It departs from a corresponding conceptualization of crisis offered by Alink, Boin, and 't Hart $(2001,290)$ who suggest that a "policy sector is in crisis when its institutional structure experiences a relatively strong decline and unusually low levels of legitimacy". Crises are frequently triggered by concrete events that "symbolize [...] the malperformance of the sector" (Alink, Boin, and 't Hart 2001, 298), and the social construction of crises depends on "audible voices"; i.e., agents that ar- ticulate "seemingly self-evident facts and images underpinning the idea that what is going on is indeed big, bad, and moreover urgent" ('t Hart and Tindall 2009, 27; italics in original).

The analytical point of departure relates to the policy subsystem; i.e., the interaction of specialized actors or "policy elites" that are involved in a certain policy domain (Baumgartner and Jones 2009; Nohrstedt and Weible 2010; Sabatier 1998). The outcome of interest is policy change. Regarding the level of policy change, the study employs the "policy proximity" criterion (Alink, Boin, and ' $t$ Hart 2001; Nohrstedt and Weible 2010). Concentrating on policy-proximate crises, the aim is thus to shed light on the processes that unfold at the level of the subsystem that is directly affected by a crisis. In explaining policy change, the study attempts to link agency and structure by (a) tracing how subsystem actors cognitively respond to crises by altering their beliefs and preferences, and (b) focusing on the emergent structure that results from individual-level processes of preference formation and communication; i.e., the structural setup of a policy subsystem, as the central explanatory factor of interest (see Nohrstedt and Weible 2010). For example, depending on whether a subsystem can be classified as unitary or adversarial prior to a crisis, different impacts on subsystem reconfigurations and policymaking are conjectured. Accordingly, while the severity of a crisis is assumed to be a poor predictor of policy change, the type of policy subsystem that is hit is the decisive moderating factor (see Hanschmann 2015). The argument is developed through a comparative case study of Fukushima's differential impact on nuclear power policymaking in Japan and Germany. Comparing cases with dif- 
ferent initial conditions, the study takes up Nohrstedt and Weible's $(2010,26)$ suggestion that comparative studies should examine the relationship between crises and policymaking across different types of policy subsystems. In so doing, this is the first contribution known to the author to systematically trace the impact of one and the same event on policy discourses and actor configurations in different jurisdictions by means of discourse network analysis.

The paper proceeds as follows: the next section gives a short overview of theoretical perspectives regarding the relationship between crises and policy change. Leaving this bird's-eye perspective, the following section more precisely details some theoretical expectations regarding the differing impacts of crises in different types of policy subsystems. The case selection is explained thereafter, followed by an overview of the methodological toolbox that is applied, along with some technical details regarding the data gathering process and some basic descriptive statistics. The empirical cases are subsequently presented and compared. In the final sections, some concluding remarks, comments on the limitations of the study, and avenues for future research are given.

\section{Theoretical Building Blocks for Assessing Change after Crisis}

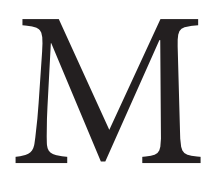

ost theoretical accounts of the policy process emphasize the decisive role of agenda setting when it comes to explaining crisis-induced policymaking. For example, the multiple streams (MS) model of agenda setting posits that "focusing events" can open up policy windows, thereby offer- ing an opportunity to alter the decision agenda as a precondition for actual policy change (Kingdon 2010). The concept of focusing events comes close to the definition of crisis given above since both terms "capture a combination of external stimuli and societal reactions" (Nohrstedt and Weible 2010, 5). However, in order to exploit a policy window before the opportunity passes, "policy entrepreneurs" have to connect the perceived problem with policy solutions and generate or exploit favorable political conditions to bring about change (Zahariadis 2007).

Concentrating on the process of issue definition and its consequences on policymaking, the punctuated equilibrium (PE) framework proceeds from the observation that "policy subsystems are subject to long periods of drift and incrementalism, only to be disrupted occasionally by bursts of frenetic policy activity" (Baumgartner and Jones 2009, 255). Periods of incrementalism are often associated with a policy monopoly: i.e., a subsystem is dominated by a single interest. Whereas policy monopolies can sustain negative feedback processes and thus policy stasis over long periods of time, focusing events may trigger major policy shifts if they lead to a redefinition of issues in the public discourse. In particular, policy equilibria might be punctuated if a favorable new policy image (e.g., a new understanding of an issue) attracts the attention of policymakers, and if issues can be assigned to receptive policy venues (i.e., institutions in which issues are decided). The punctuation of policy equilibria is therefore associated with positive feedback processes: "Small inputs can cascade into major effects as they work their ways through a complex system" (Baumgartner and Jones 2009, 16). 
The importance of issue definition and agenda setting in explaining crisis-induced policymaking is also highlighted in the crisis management literature. Based on a series of case studies, Boin, 't Hart, and McConnell $(2009,82)$ conclude that crises "typically generate a contest between frames and counter-frames concerning the nature and severity of a crisis, its causes, the responsibility for its occurrence or escalation, and implications for the future". Thus, it can be assumed that political discourse plays a crucial role in post-crisis policymaking processes because both change- and status quo-advocates will make use of discursive strategies for setting the agenda in order to promote their respective demands and proposals in the policy subsystem (Boin, 't Hart, and McConnell 2009; Hurka and Nebel 2013).

As Schmidt and Radaelli (2004, 192) argue, a research focus on discourse "can serve to bridge the gap between [...] structure and agency" in the study of policy change since discourse is "fundamental both in giving shape to new institutional structures" as a system of claims and ideas about new values, rules, and procedures "and as a resource used by entrepreneurial actors to produce and legitimate those ideas" within a process of interaction and persuasion based on the mutual exchange of claims. Explaining policy outputs by means of actor-centered discourse analysis can thus be related to James Coleman's (1990) structural individualist style of explanation. Accordingly, a structural association between both macro stimuli (such as crises) and outcomes of interest (such as policy changes) requires a microfoundation that-to put it simply-takes agents and their interactions into account. "After all" as Schmidt and Radaelli
$(2004,192)$ aptly put it, "if the structure changes [...] there must be some political processes through which specific actors have modified the structure".

However, the approaches mentioned so far are relatively weak in theorizing how actors coordinate in order to bring about or prevent policy change after crises (Schlager 2007, 302-303). The Advocacy Coalition Framework (ACF), on the other hand, puts considerably more weight on post-agenda-setting processes and patterns of actor coordination. According to the ACF, actors who share a particular set of basic normative and causal beliefs and who permanently engage in coordinated behavior in order to achieve shared objectives can be grouped into so-called advocacy coalitions (Sabatier 1998, 103). The main outcome of interest to the ACF is policy change, with "major" policy change understood as modifications in the policy core aspects of a governmental program while "minor" change implies policy alterations that are limited to secondary aspects such as the calibration of certain policy instruments (Sabatier and Jenkins-Smith 1999, 147). Crises, which are subsumed under the fairly broad category of external perturbations, are assumed to provide a path toward major policy change in a subsystem "by shifting and augmenting resources, tipping the power of coalitions, and changing beliefs" (Weible, Sabatier, and McQueen 2009, 124). In particular, ACF scholars have emphasized that opportunities for major change will not materialize unless they are "skillfully exploited by proponents of change" (Sabatier and Jenkins-Smith 1999, 148). Yet, as Dudley $(2007,409)$ notes, "this leaves open not only the question of exactly how the proponents of change will exploit the sit- 
uation, but also the effects on a coalition over time". Drawing on earlier works primarily by Howlett and Ramesh (1998) and Nohrstedt and Weible (2010), this contribution assumes that the structure of a policy subsystem is a decisive factor in understanding crisis impacts on policymaking, and it additionally argues that policy discourse is the appropriate level of analysis for empirically ascertaining the evolution of actor constellations in a given policy subsystem.

\section{Subsystem Structures as Determi- nants of Policy Change}

ccording to Howlett and Ramesh
(1998, 475), the nature of a poli-
cy subsystem "reveals a great deal about its propensity to respond to changes in ideas and actors, and is therefore a good indicator of both the nature [...] and tempo [...] of policy change likely to occur in that sector". Building on the concept of knowledge-based "policy communities" that are bound together by shared policy ideas, subsystems can either be contested or dominated by a "monopolistic or hegemonic community" (Howlett and Ramesh 1998, 471). In the latter case, a dominant set of ideas exists which remains largely unchallenged by alternative policy ideas, whereas in the former, several sets of policy ideas compete for dominance and the policy community space is contested rather than monopolized.

A somewhat more focused perspective that classifies policy subsystems according to the number of coalitions and patterns of interaction is offered by the ACF. If a policy subsystem contains a single advocacy coalition that is characterized by high degrees of belief congru- ence and coordination, it can be classified as unitary. At the other end of the spectrum, adversarial policy subsystems are characterized by two or more competitive coalitions with "incompatible beliefs and different patterns of coordination" (Weible 2008, 625). As an alternative to the categorical classification of policy subsystems, their structure can be described by reference to a scale of subsystem polarization, with low degrees of polarization between the subsystem actors implying a unitary structure and high degrees of polarization corresponding to an adversarial structure. Beyond that, the conceptual distinction between dominant and minority coalitions is central to the ACF. Whereas majority of the members of dominant coalitions are in positions of formal authority, minority coalitions need to target other venues in order to influence public policymaking (Sabatier and Weible 2007, 203) ${ }^{1}$.

As concerns the pathways that link policy-proximate crises and policy change, the structural setup of a policy subsystem has been hypothesized to play an important role (Nohrstedt 2007; Nohrstedt and Weible 2010). More specifically, to begin with, a policy subsystem that can be classified as unitary prior to a crisis is unlikely to translate post-crisis demands for change into policy shifts that go beyond symbolic changes or adjustments in secondary aspects. In this type of setup, most members of the policy monopoly can be expected to "tone down the policy implications that potentially emerge from the crisis" (Nohrstedt and Weible 2010, 23). In order to reduce cognitive dissonance, actors rely on mechanisms such as downplaying counterevidence and selectively exposing themselves to stimuli (Festinger 1985), 
thereby avoiding encounters with information that is inconsistent with pre-existing values and beliefs (i.e., the status quo). Since the core aspects of a policy are thus likely to remain intact even under crisis conditions, unitary subsystems may be associated with relative policy stability or only minor changes at best. However, it seems likely that hegemonic coalitions in unitary subsystems are challenged by newly emerging coalitions in crisis situations. New coalitions might include actors who were not previously part of the subsystem, as well as defectors from the hegemonic coalition. This could in turn alter the subsystem setup in the long run, "shifting the dominant mode of subsystem interaction from unitary to adversarial" (Nohrstedt and Weible 2010, 23). Ultimately, this could increase the likelihood of major policy change at a later point in time.

The likelihood that a radically new understanding of a problem and new policies are developed under crisis conditions should be greater in an adversarial setup. Whereas unitary subsystems are "closed and inhospitable", adversarial subsystems are more "open to new actors and hospitable to fresh ideas" (Howlett and Ramesh 1998, 473). In this kind of setting, the seed for the rejection of the status quo is already sown prior to a crisis, and competition between the coalitions in the "policy crisis exploitation game" (Boin, 't Hart, and McConnell 2009,90 ) increases the availability of alternative interpretations and policies that can be attached to a problem (Birkland 2006; Kingdon 2010). Suggesting plausible pathways for post-crisis policymaking dynamics, Nohrstedt and Weible (2010, 23) propose that the redistribution of resources in adversarial subsystems might give one coalition "the upper hand, leading to minor or major policy changes" and in some cases even to the collapse of one coalition "and the emergence of a unitary policy subsystem". As an alternative scenario, they propose that crises might lead to an intensification of polarization and conflict between coalitions.

This contribution argues that the proposed pathways might be complementary rather than exclusive, and that timing is an important factor to keep in mind when hypothesizing pathways between crisis and policy reactions. It therefore suggests a two-step model to explain post-crisis policymaking dynamics in adversarial subsystems. In line with the literatures on framing contests and cognitive dissonance theory, a policy-proximate crisis is likely to trigger a temporary increase in subsystem polarization as a first step. However, crises create situations in which key agents are "highly mobile in their behaviour in order to promote new ideas, reshape perceptions, and reconstruct issues" (Dudley 2007, 407). Minority coalitions and policy entrepreneurs play a key role in these processes. They will usually try to capitalize on pre-existing policy conflicts in order to underscore their legitimacy through questioning the status quo. While minority coalitions do not dispose of decision making authority, they can be expected to engage in "intensified efforts to influence public opinion" and "strategic use of information" (Nohrstedt and Weible 2010, 16). Hence, they may be able to tilt the discursive and ultimately the policy equilibrium through percolating demands for change, policy proposals and a new policy image into the dominant coalition. Because "new ideas and their attendant policy frames often 'capture' all stakeholders" 
(Richardson 2000, 1021), the collapse of the policy image previously employed by the dominant coalition becomes more likely, as do subsequent policy changes. In adversarial subsystems, increasing polarization might thus not be the end of the story, but instead constitute one of the necessary cogs and wheels that link crisis and major policy change.

To sum up the theoretical expectations developed so far, the existence of an adversarial policy subsystem is necessary but not sufficient for major policy change to occur under crisis conditions, whereas a unitary subsystem is sufficient but not necessary for policy stability. For alternative policy ideas to be converted into non-incremental changes in adversarial subsystems, however, minority coalitions need to seize upon the opportunities provided by a crisis and policy entrepreneurs need to convince dominant coalition members that changing policies is the right thing to do. In the following parts of the study, the theoretical propositions about the crisis-policy change link will be explored empirically. Note that the theoretical claims regarding the sufficiency and necessity of conditions are intentionally expressed in a pointed manner, but that they cannot be subjected to formal testing due to the limited number of cases. The analysis is nevertheless assumed to be appropriate for assessing the plausibility of the underlying reasoning.

\section{Case Selection}

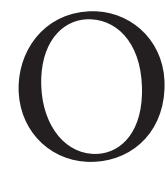
n March 11, 2011, the Tohoku seaquake caused a massive tsunami that struck 14 Japanese coastal nuclear reactors belonging to four different nuclear power plants (NPPs).
The meltdown of the four units at the Fukushima Daiichi power plant triggered crises in the nuclear power policy sectors in a number of countries and thus offers an excellent starting point for comparatively investigating the theoretical propositions outlined above. Two cases whose institutional settings experienced particularly strong declines after the Fukushima meltdown are Japan and Germany. In Japan, public anxiety after the accident was initially centered around disaster management, led to blame games among the political elites and public questioning of the capacity of authorities to deal with disaster relief, and later on also challenged the legitimacy of nuclear power in its entirety. In Germany, the Fukushima incident increased the general level of attention paid toward nuclear power policy, gave room to articulate pro-change advocates and further diminished political and overall societal support for the given institutional structure.

Selecting cases for empirical investigation should not be "dictated by the most readily available [...] materials" (George and McKeown 1985, 42) and it is important to keep in mind that "the cases you choose affect the answers you get" (Geddes 1990). Japan and Germany, however, are particularly suitable cases for assessing the crisis-policy change relationship across different types of policy subsystems since they represent typical cases of unitary (Japan) and adversarial (Germany) policy subsystems.

Japan's political-economic structure is characterized by a particularly rigid form of sectoral differentiation and a corresponding compartmentalization of policy networks (Lehmbruch 1995). The sectoral integration enables vertical mobility of actors within sectors, but 
strongly inhibits horizontal mobility between different sectors. Vertical mobility means that civil servants move between high-profile positions in the private sector or public enterprises. This standard operating procedure is called amakudari in Japan (see Colignon and Usui 2003). Moreover, it is common practice that former public administration employees continue their careers as members of the Diet. These peculiarities have favored the emergence of a successful policy monopoly in the nuclear policy subsystem which was backed by a closed policy community composed of policymakers, government agencies, utilities and nuclear vendors, as well as the mass media, the financial sector, judicial actors, and academic circles (Kingston 2012; Koch 2001). This so-called "nuclear village" has been built by the "guiding hand of the government" (Valentine and Sovacool 2010, 7973) since the 1950s, and henceforth has developed unchallenged dominance within the policy subsystem. Encountering "low levels of civic activism" (Valentine and Sovacool 2010, 7975), interaction patterns between regulatory agencies, utilities, and Diet members in particular from the Liberal Democratic Party (LDP) were for decades characterized by close cooperative ties. These properties facilitated the fact that the "nuclear regulators have long regulated in favor of the regulated"; a phenomenon that is known as regulatory capture (Fam et al. 2014; Kingston 2013).

Similar to Japan, Germany launched its nuclear program in the 1950s, with the first experimental reactor starting in 1960 and "giant German corporations" like AEG, Siemens, and ThyssenKrupp leading the way in the emerging industry (Jahn and Korolczuk 2012, 159). Whereas support for the technology initially remained fairly high among the population and all relevant political parties, it began to wane in the 1970s. In particular, anti-nuclear protests at the reactor sites in Whyl and Brokdorf gave rise to a strong and enduring anti-nuclear movement. Emerging from this movement, the Green Party gained representation in the Bundestag in 1983. In light of the Chernobyl catastrophe, the Social Democratic Party (SPD) became the second political party to oppose nuclear power in 1989. Since the incumbent conservative-liberal government remained committed to nuclear power, it took another decade until a phase-out law was eventually passed by the new government consisting of SPD and Greens (Glaser 2012). However, pro-nuclear advocacy by conservatives and liberals engendered another backlash and a revision of this so-called "nuclear consensus", resulting in the extension of the lifetime of 17 nuclear plants as codified in October 2010. What can we learn from this brief history of nuclear power politics in Germany? First, that a number of critical events have created high levels of enduring anti-nuclear public opposition, and second, that this opposition has materialized in the form of a sharp partisan cleavage in the German party system. Setting the German case apart from the Japanese, this highlights the adversarial character of the nuclear power policy subsystem in Germany.

One caveat with regard to the selection of cases needs to be addressed here. Regarding the criterion of geographic proximity, Japan is unique in representing an "immediate crisis" case (Nohrstedt and Weible 2010). However, the fact that Japan was hit by a nuclear disaster of such a magnitude can be assumed to add some propensity to a policy wise crisis reaction, 
compared with geographically more peripheral cases. Crisis immediacy thus increases the burden of confirming the theoretical propositions that apply to unitary subsystems.

\section{Methodological Approach: Dis- course Network Analysis}

$\mathrm{I}$

$\mathrm{n}$ most policy subsystems, and of particular relevance to conditions of crisis, "policy experts operate within the terms of political discourse" (Hall $1993,289)$ in order to communicate their "demands, criticisms, or proposals" - in short, political claims (Koopmans and Statham 1999)2. The conveyance of political claims is a complex interactive process that usually takes place in public fora such as news media. Once an actor publicly articulates a claim about a certain issue, others feel encouraged to do the same. The interplay of approving and dissenting views creates patterns of repeated interaction (Leifeld 2013). The attempt to analyze political discourse has brought about a multitude of research approaches and strategies. Although appealing in regard to the detail provided concerning the exploration of narratives and interpretive frames, previous approaches to discourse analysis have only cursorily touched on the concrete linkages between policy discourses and public policymaking (see, e.g., Hajer 1993; 1995; Dryzek 1997). What is more, these qualitative approaches have grave methodological problems as regards their transparency and replicability.

In order to connect discourse analysis more closely with policy studies, a formalized methodological approach was developed more recently (Janning et al. 2009, 71-75). Discourse network analysis is based on the actor-centered and relational policy network approach. Whereas the "classical" study of policy networks concentrates on relational structures based on categories such as power, influence, or resource exchange, discourse network analysis is designed to describe and explain actor relationships on the basis of cognitive concepts like beliefs, claims, or frames. It thus corresponds to the perspective that political discourse can be analytically decomposed into a substantive layer of policymaking, on the one hand, and coordination and interaction of actors as the relational layer on the other (Schmidt and Radaelli 2004, 184). In contrast to less formalized approaches, discourse network analysis is a transparent and replicable tool that allows for the systematic and quantitative study of policy discourse.

Formally, a discourse network consists of a defined set of actors $(A)$ and a defined set of concepts $(C)$. The former contains a number of actors $a_{1}, a_{2}$, etc., thus $A=\left\{a_{1}, a_{2}, \ldots, a_{\mathrm{m}}\right\}$, and the latter includes a number of concepts $c_{1}, c_{2}$, etc., thus $C=\left\{c_{1}, c_{2}, \ldots, c_{\mathrm{n}}\right\}$. Actors can express approval or rejection of concepts through statements in a policy discourse. Hence, statements are the unit of analysis and constitute the relata between $A$ and C. Discourse network analysis takes into account the fact that public discourse is a sequential phenomenon. By explicitly modeling time and allowing the decomposition of discourse networks into sequential time slices, the method helps to examine the temporal dynamics of discourses.

From the basic model, different types of discourse networks can be derived. An affiliation network is a graph 


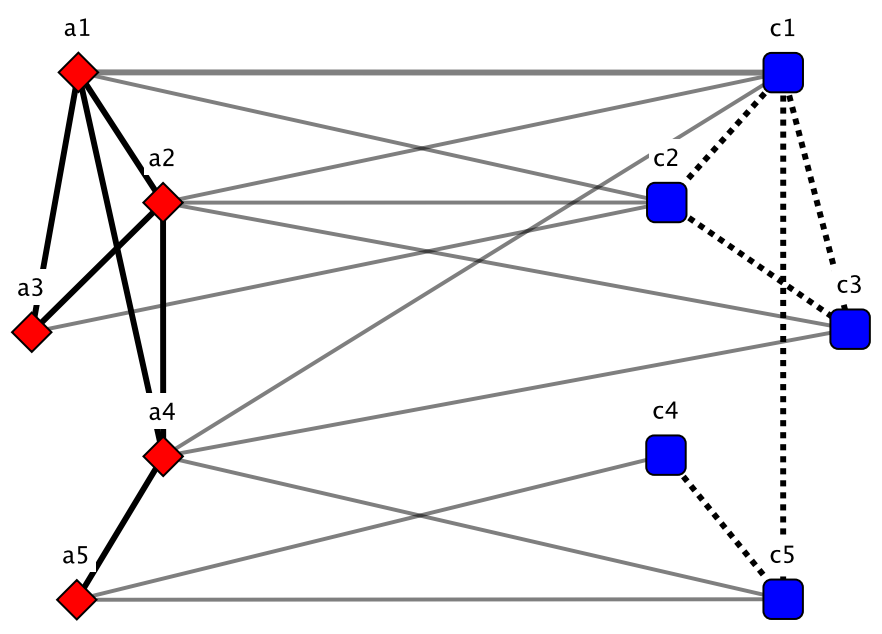

\section{Figure 1.}

Basic discourse network model, based on Janning et al. $(2009,71)$. Notes: red squares correspond to actors $\left(A=\left\{a_{1}, a_{2}, \ldots, a_{5}\right\}\right)$ and blue boxes indicate concepts $\left(C=\left\{c_{1}\right.\right.$, $\left.\left.c_{2}, \ldots, c_{5}\right\}\right)$. Grey edges represent the affiliation network between $A$ and $C$, solid black edges represent the actor congruence network, and dashed edges indicate the concept congruence network

that depicts the relations between a set of actors and a set of concepts. It enables analysis of how the usage of certain concepts in a discourse evolves over time and to what extent actors' affiliations to concepts change. However, when the interest lies with the structural evolution of a policy subsystem, actor congruence networks are more helpful. They permit the examination of properties such as the number of discourse coalitions, the degree of network polarization and subsystem re-configurations over time. Analogously, a concept congruence network can be generated from the original discourse data. Figure 1 visualizes the basic discourse network model and clarifies how the different network types relate to each other. For a detailed description of the method and network types, the reader is referred to Leifeld's $(2010 ; 2011 ; 2013)$ work.

\section{Obtaining Discourse Data}

The comparison of nuclear power policy discourses around Fukushima in Japan and Germany relies on one high-quality daily newspaper for each country. It can be assumed that news media data "capture a wider variety of political actors" than other sources (Leifeld 2013, 195); moreover, they are published frequently and can thus generate a solid empirical base for systematic investigations. For Japan, data were gathered from the newspaper "Yomiuri Shimbun", and for Germany from the "Süddeutsche Zeitung". Both newspapers were select- 
ed according to the "quality press" criterion (Barranco and Wisler 1999); i.e., they represent general news-oriented papers of high reputation and are known to be politically moderate. Both claim to be independent, have at least nationwide circulation and can be considered national in terms of their coverage of the policy discourse of interest. Moreover, both newspapers were published throughout the period of investigation and did not experience substantial editorial changes, which makes them "likely to show a high-degree of reliability over time" (Barranco and Wisler 1999, 303).

The strategy of selecting not more than one newspaper per country could be confronted with the critique that a single newspaper is likely to miss important components of the discourse, thus leading to biased discourse data. In opposition to this objection, Barranco and Wisler $(1999,303)$ argue that one newspaper is usually sufficient in an analysis of newspaper data; first, because "the use of a single national newspaper is particularly cost effective" due to limited additional benefits from other sources with regard to coverage of further events, and second, because the initial bias encountered when relying on a single national newspaper is not lessened to a significant degree if a second newspaper is involved (Barranco and Wisler 1999, 308; see also Leifeld 2013, 177).

\section{Coding Procedure}

The coding of statements that were published in newspaper articles was conducted with the software Discourse Network Analyzer (DNA 1.0, see Leifeld 2009). The starting point of the coding process involved a search for ar- ticles in the electronic archives of both newspapers. In order to identify the relevant articles, a search string including the truncated terms NPP, Atomic, Nuclear, Energy Policy, and Fukushima was used. All articles identified through this string which were published within the period of investigation (see below) and contained at least one statement that represented a claim about nuclear power policy were entered into the software. Each statement was then coded manually according to five variables: first, the date when the statement appeared in the respective newspaper; second, the name of the actor who made the statement (considering both individual and complex actors); third, the organization to which the actor belonged or was associated; fourth, the concrete claim which was revealed in the statement; and fifth, whether the actor approved of or rejected the claim.

In order to make the coding process as transparent as possible, a finegrained coding manual was developed ${ }^{3}$. After a preliminary qualitative content analysis of 50 newspaper articles and throughout the research process the initial coding scheme was subject to modification and strategies of aggregation. The coding of statements depends to a certain degree on the background knowledge and interpretive abilities of the coders ${ }^{4}$. In order to rule out as much ambiguity as possible, the main coders for both cases under examination were native speakers of the language the publications were written in. This is a major benefit since the expression of claims is to some extent bound to cultural norms and habits, and native speakers are usually more familiar with these peculiarities than non-native speakers. 


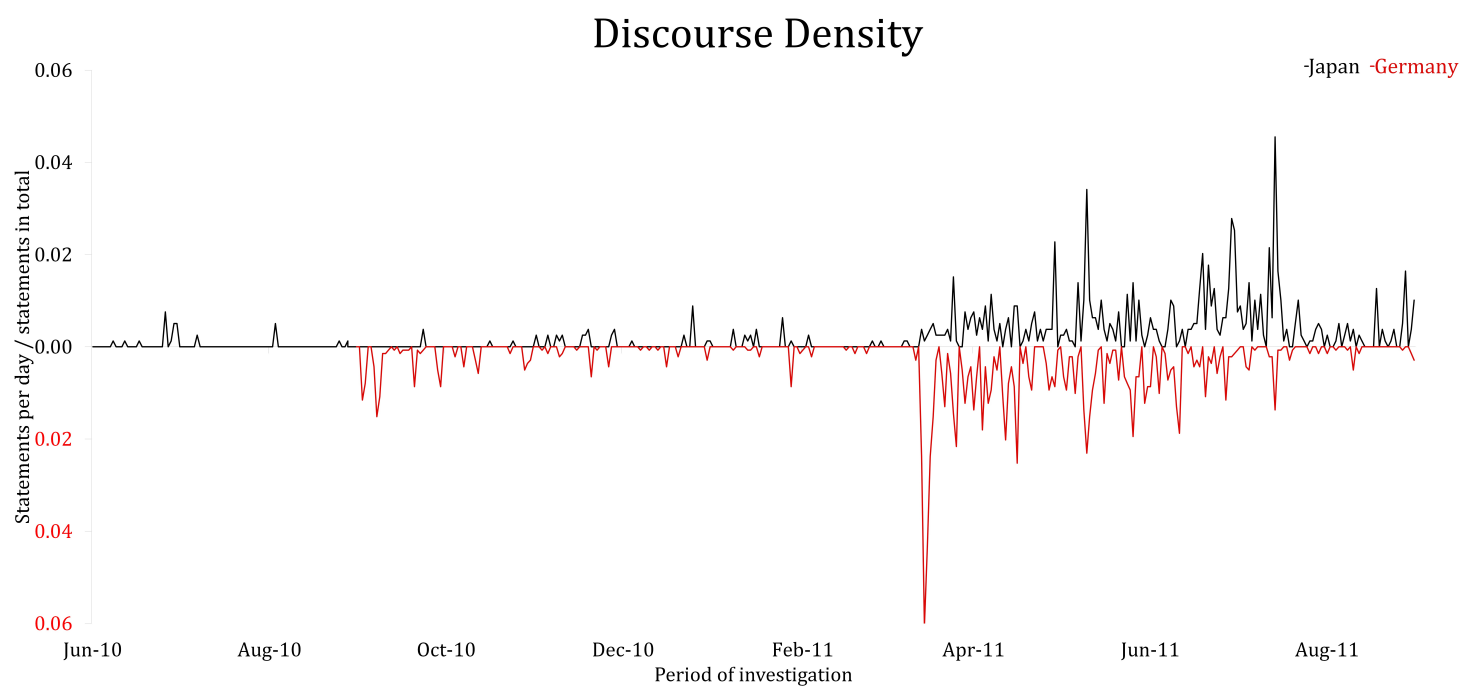

Figure 2.

Density of the nuclear power policy discourse before and after 3/11 in Japan (black) and Germany (red). Notes: The $x$-axis maps the period of investigation; the $y$-axis entails the standardized statement density (i.e., the ratio of statements per day/statements in total). In order to ease readability, the $x$-axis is mirrored for the German case. Discourse data have been obtained from Yomiuri Shimbun (Japan) and Süddeutsche Zeitung (Germany)

Boundary Specification: Delimiting the Nuclear Power Policy Subsystems

Based on Laumann, Galaskiewicz, and Marsden (1983), many social network analysis-themed textbooks distinguish between realist and nominalist strategies for specifying the boundaries of a network. According to the realist approach, boundaries are defined by the subjective perceptions of the network actors. Hence, it is assumed "that a social entity exists as a collectively shared subjective awareness of [...] the actors who are members" (Laumann, Galaskiewicz, and Marsden 1983, 21). While this approach is sometimes applicable to the study of entities that are characterized by some form of closed membership, policy subsystems' boundaries are fluent vis-à-vis adjacent subsystems, undergo constant changes in terms of their constituent actors and "contain an uncountable number of components" without formal membership (Nohrstedt and Weible 2010, 7). Accordingly, the boundary specification in this study is conducted on the basis of the concrete research purpose, and specific properties that demarcate the set of integrated actors from the set of nonintegrated actors are defined by the researcher-a process corresponding to the nominalist approach.

In principle, any actor who conveys at least one claim with regards to nuclear power policy in the respective newspaper belongs to the Japanese or the German nuclear power policy subsystem. However, since interaction patterns among the policy elites are at the core of the study, private persons are not included (e.g., participants of an anti-nuclear demonstration). Moreover, journalists 
are conceptualized as transmitters but not as participating protagonists of the policy discourse, and are therefore excluded as well, with the exception of journalists who are cited according to their function as "policy specialists" with strong parallels to scientific actors. On the other hand, in line with the concept of policy elites, the following types of actors are within the discourse network boundaries: political actors from all levels of government and opposition, actors representing a state's bureaucratic agencies, nongovernmental organizations (NGOs) such as environmental or religious actors, actors representing associations and interest groups, scientists and scientific organizations, actors representing businesses, and actors representing international organizations.

\section{Period of Investigation}

In order to compare and explain the evolution of nuclear power policy in Japan and Germany after Fukushima, the policy discourses are subjected to sequential pre-post-comparisons. The period of investigation starts on June 1, 2010 for Japan, and September 1, 2010 for Germany. For both cases, it ends on August 31, 2011. The different starting points take into account the fact that the unfolding of the pre-Fukushima policy discourses evolved quite differently in both countries. Whereas nuclear power policy was a very contentious topic in Germany even before Fukushima, few claims were made with regard to the issue in Japan until March 2011. Due to the relatively low statement density in Japan before the crisis (see the black line in Figure 2 and the note in the caption about statement density), a time frame of about nine months was considered necessary for drawing meaningful inferences concerning the spatial setup of the pre-Fukushima nuclear power policy subsystem. The endpoint was chosen because it coincides with a change of government in Japan-when nuclear power policy was (temporarily) removed from the governmental agenda-and because policy activism in Germany had come to an end by this point.

\section{Nuclear Power Discourses before and after Fukushima}

The discourse networks for Japan
and Germany rely on 1,981 state-
ments that were reported in 755 newspaper articles ${ }^{5}$. Table 1 depicts the absolute numbers for both countries. The number of articles is somewhat higher for Japan, but factoring in the longer period of observation, both cases are comparable regarding the ratio of articles per day. The number of statements is higher for the German case, reflecting the slightly different style of newspaper reporting in Germany which is characterized by more comprehensive articles and greater usage of quotations.

For the purpose of tracing the evolution of nuclear power policy discourses around the Fukushima accident, the subsequent analysis concentrates on actor congruence networks. In these onemode networks, actors are represented by squares. Squares are linked by edges if actors employ common claims in the discourse. Edge weights $w_{\mathrm{t}}\left(a, a^{\prime}\right)$, which are depicted by edge width, indicate the degree of consensus between two actors $a$ and $a^{\prime}$. Hence, the higher $w_{\mathrm{t}}\left(a, a^{\prime}\right)$, the higher the number of claims shared by $a$ and $a^{\prime}$. In order to eliminate the effect of statement frequency on edge weight, 
Table 1. Descriptive statistics: media coverage of nuclear power policy in Japan and Germany. Notes: The period of investigation starts earlier for Japan (June 1, 2010) than for Germany (September 1, 2010). The last date included for both countries is August 31, 2011

\begin{tabular}{lcccc} 
& Articles & Articles/Day & Statements & Actors \\
\hline Japan & 447 & 0.978 & 789 & 261 \\
\hline Germany & 308 & 0.844 & 1,192 & 284
\end{tabular}

Leifeld (2011) proposes normalizing edge weights, $\Phi\left(w_{\mathrm{t}}\right)$. In order to clarify the structural properties of the networks, threshold values are set to normalized edge weights, with edge weights below a certain value excluded from the network visualization. This procedure helps with assessing the structure of complex networks. In relation to determining the optimal threshold, the value should be increased "in a stepwise fashion until the structure of the discourse network becomes visible" (Leifeld 2013, 176). Since the most appropriate threshold values depend on several factors such as the number of concepts, or the size of the time slice, $\Phi\left(w_{\mathrm{t}}\right)$ cannot be meaningfully compared across different actor networks.

In order to assess the structural properties of actor congruence networks, two measures are employed. Network density $d_{t}$ relates the number of realized edges (numerator) to the maximum possible number of edges (denominator) in a network. Thus, the density of a discourse network is high "if everyone is connected to everybody else" and low "if the graph is multipolar" (Leifeld 2010, 22). Since $d_{\mathrm{t}}$ is bounded between 0 and 1 , its complementary value $p_{\mathrm{t}}=1-d_{\mathrm{t}}$ can be employed as an intuitive way to capture network polarization. A second option to assess the structure of a subsystem is provided by the Girvan-Newman clustering algorithm (GNA). The GNA uncovers "community structures" of network graphs by removing edges with high betweenness values (Girvan and Newman 2002). In the actor congruence networks, different clusters or policy communities are visualized by different background colors. Based on the visualizations, conclusions with regards to the congruence of different actors can be drawn by reference to the interconnectedness of vertices and community structures detected by the GNA. Both the spatial distance between vertices and their coordinates, on the other hand, cannot be meaningfully interpreted (see Leifeld 2013).

Computation of edge weights and densities as well as the visualization of discourse networks was conducted with the software visone 2.10 (Brandes and Wagner 2004). The network layout follows a classical multidimensional scaling technique based on stress minimization of graph-theoretic distances (Brandes and Pich 2009). Square color corresponds to actor type, as follows: orange indicates 
federal/central government, purple indicates parliamentary opposition,

indileates actors from the sub-nationall level, green indicates nongovernmental organizations, red indicates associations and interest groups, pink indicates international organizations (incl. EU-actors), grey indicates federal agencies, yellow ofoclicates selence, dark blue indicates business, and black indicates the utility companies that run nuclear power plants ${ }^{6}$.

For both Japan and Germany, the discourse analyses are based on three sequential time slices that are arranged in light of relevant political events (see below). Whereas the first actor congruence network for each country plots the pre-crisis subsystem setup und thus helps to explore the structural conditions for crisis-induced policy change, the subsequent graphs allow to assess the discursive processes that took place after the Fukushima accident.

\section{Japan: From Unity to Polarization}

Status Quo Ante: Nuclear Power Policy before $3 / 11$

1 igure 3 shows the actor congruence network for the nuclear power policy discourse in Japan between June 1, 2010 and the day of the quake. The network includes 38 actors, most of which represent subnational polities, central government, the nuclear industry, and utilities. Both the relatively high density value $(d=0.35)$ and the result of the Girvan-Newman clustering provide evidence that the subsystem was largely unitary prior to the crisis, with subsystem actors being bound together by shared policy beliefs, preferences, and interests.
More specifically, the GNA indicates that the discourse space was inhabited by a single policy community which might be called the "nuclear village". The congruence network, hence, corroborates what we already know about the pre-crisis properties of the Japanese nuclear power policy subsystem (see the paragraph on case selection).

Taking a closer look at the concrete policy claims helps with understanding the predominant policy image put forward by the members of the nuclear village. In line with the "New Energy Strategy" published by the Minister of Economy, Trade and Industry (METI) in 2006, several government representatives including Prime Minister N. Kan and METI M. Naoshima claimed that Japan should take the lead in the "nuclear renaissance"; i.e., the global revival of the nuclear power industry, through exports of domestic nuclear technology. This endeavor was supported by the big players of the Japanese nuclear industry that had been nurtured by the state for long periods of time, such as Hitachi and Toshiba (see Valentine and Sovacool 2010), as well as the influential business federation Nippon Keidanren (NK) and several of the 10 regionally organized private electricity utilities, including Kyushu Electric Power Company (KYEPCO), Chubu Electric Power Company (CEPCO), and Tokyo Electric Power Company (TEPCO). The Presidents of the latter also called for domestic nuclear new build, and reiterated their belief that nuclear power is a safe technology. This view was shared by several other actors, among them the director of the Seismic Safety Office at the Nuclear and Industrial Safety Agency (NISA), M. Kobayashi. Numerous politicians from the sub-national level (such as the Gov- 


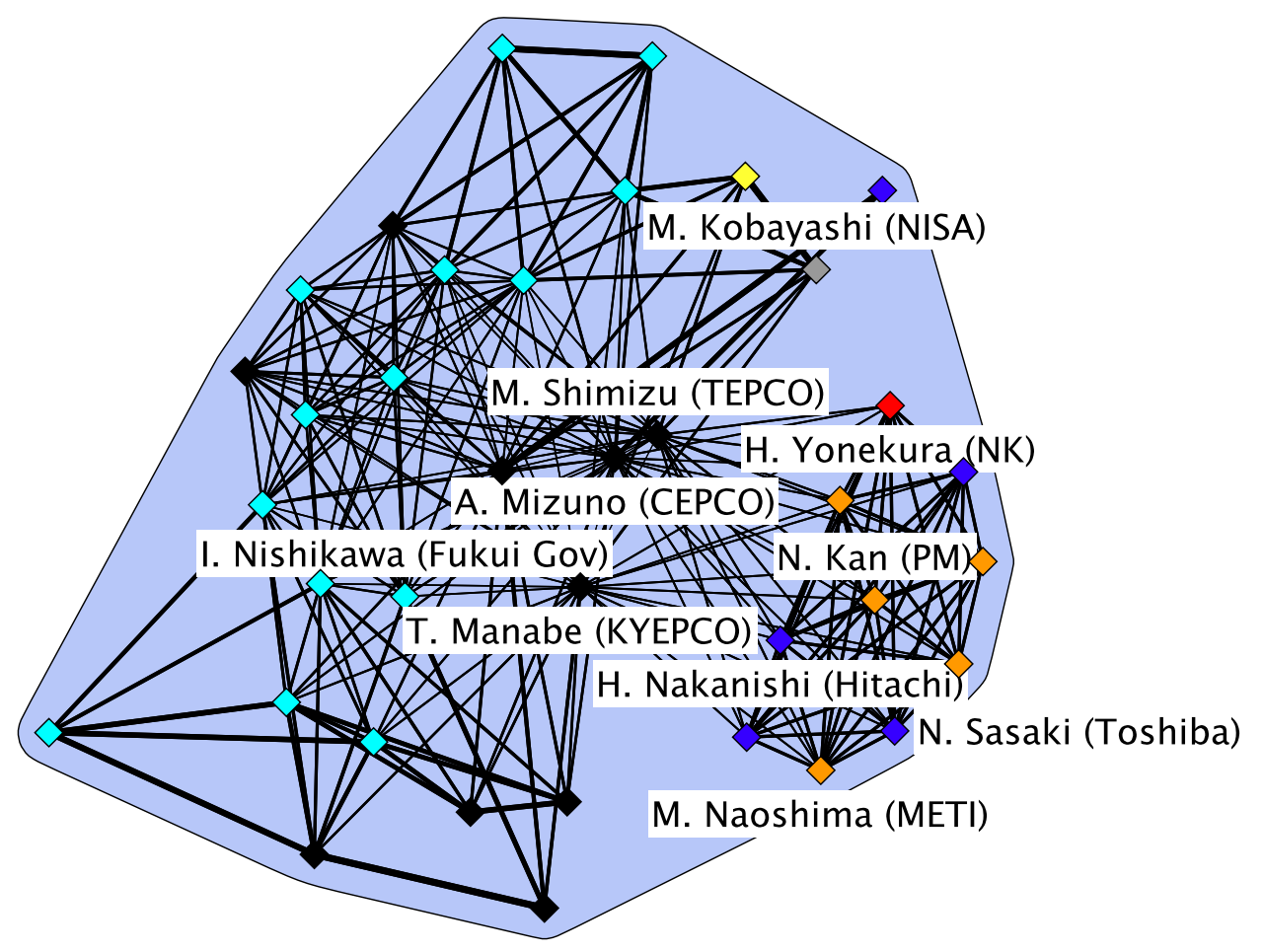

Figure 3. Normalized Actor Congruence Network, June 1, 2010-March 11, 2011 $(\Phi(w) 0.016, p=0.65)$

Table 2. Nuclear Power Policy after Fukushima in Japan: Important Stages. Sources: Kingston (2013) and newspaper articles from Yomiuri Shimbun and The Japan News

\begin{tabular}{ll} 
May 6,2011 & The government orders the shutdown of the NPP in Hamaoka due to earthquake risk. \\
\hline July 6,2011 & $\begin{array}{l}\text { "Stress tests" are announced by Industry Minister Kaieda. Within the next } 10 \text { months, } \\
\text { all NPPs are shut down for safety inspections. }\end{array}$ \\
\hline July 13,2011 & PM Kan announces to lower Japan's dependence on NP in stages. \\
\hline August 26,2011 & The Diet passes a bill to increase the share of renewable energies. \\
\hline August 30,2011 & After the resignation of N. Kan, Y. Noda is elected new PM. \\
\hline May 5, 2012 & After the shutdown of the Tomari reactor no. 3, all Japanese NPPs are off the grid. \\
\hline $\begin{array}{l}\text { September 14, } \\
2012\end{array}$ & $\begin{array}{l}\text { The Noda cabinet endorses a gradual phase-out policy, but backpedals only several } \\
\text { days later. }\end{array}$ \\
\hline $\begin{array}{l}\text { December 16, } \\
2012\end{array}$ & The election of the new Shūgiin turns out with a landslide victory of the LDP. \\
\hline
\end{tabular}

December 26 , 2012
New PM S. Abe (LDP) announces (a) to restart idled NPPs, (b) to promote nuclear new build, and (c) to push development of renewable energies. 
ernor of the Fukui prefecture) connected the positive image of nuclear power as a safe and reliable energy source to calls for safety retrofits of NPPs. Nevertheless, the predominant pre-crisis policy image of nuclear power was not contested by alternative policy ideas. Being "widely accepted and generally supportive of the policy", this pro-nuclear image can be associated with the "successful policy monopoly" of the nuclear village (Baumgartner, Jones, and Mortensen 2014, 67).

Nuclear Policy Discourse in the Wake of $3 / 11$

Table 2 gives an overview of important policy developments that unfolded after the Fukushima accident in Japan. While there was no major policy shift that would have created a new path for nuclear power in Japan, several minor measures were implemented by the government in response to the crisis. The first decision that went beyond direct crisis management provisions was the shutdown order targeted at the Hamaoka plant on May 6, 2011. Put forward by Prime Minister Kan, the decision was justified by Hamaoka's high earthquake risk. Representing the first and second local maximum of discourse density after $3 / 11$ (see Figure 2 , with local maxima referring to density values $>0.02$ ), it was accompanied by a framing contest in an increasingly polarizing subsystem. Pro-nuclear advocates accredited the Fukushima accident to forces of nature and depicted 3/11 as an event exceedingly unlikely to reoccur. Whereas these actors played down possible policy implications that might go beyond making improvements in crisis preparedness, the emerging opposition acknowledged both the hazardous char- acter of nuclear fission and Japan's susceptibility to further quakes. Moreover, these actors framed 3/11 as an event not solely attributable to nature, in doing so calling for a re-evaluation of Japan's nuclear policies. The emergent subsystem polarization is mapped in the actor congruence network for the first eight weeks after the Tohoku quake (see Figure 4).

According to the GNA applied to the actor congruence network, the subsystem actors can be grouped into three communities representing more or less coherent bundles of claims or policy images. The community displayed on the yellow background contains 16 actors that were bound together by "business-as-usual" (BAU) claims. Downplaying Fukushima's significance for nuclear policy, this pro-nuclear coalition argued in favor of making continued efforts to promote nuclear exports and rapidly restarting nuclear reactors currently off the grid. The coalition contained important actors from the nuclear village such as Toshiba's CEO (N. Sasaki), CEPCO's President (A. Mizuno), as well as NISA representative T. Hashimoto. In tandem with other pro-nuclear players from politics, nuclear industry, and utilities, they continuously depicted nuclear power as a safe technology, partly also framing the technology as an important contributor to climate change mitigation efforts.

The actor congruence network illustrates a strong increase in subsystem polarization $(p=0.87)$, with two further policy communities emerging. These called for a review of the nuclear policy framework (blue background) or, more radically, for a rapid nuclear phase-out (green background). Containing 25 actors, the "safety coalition" (blue) advocated safety improvements and a general, 


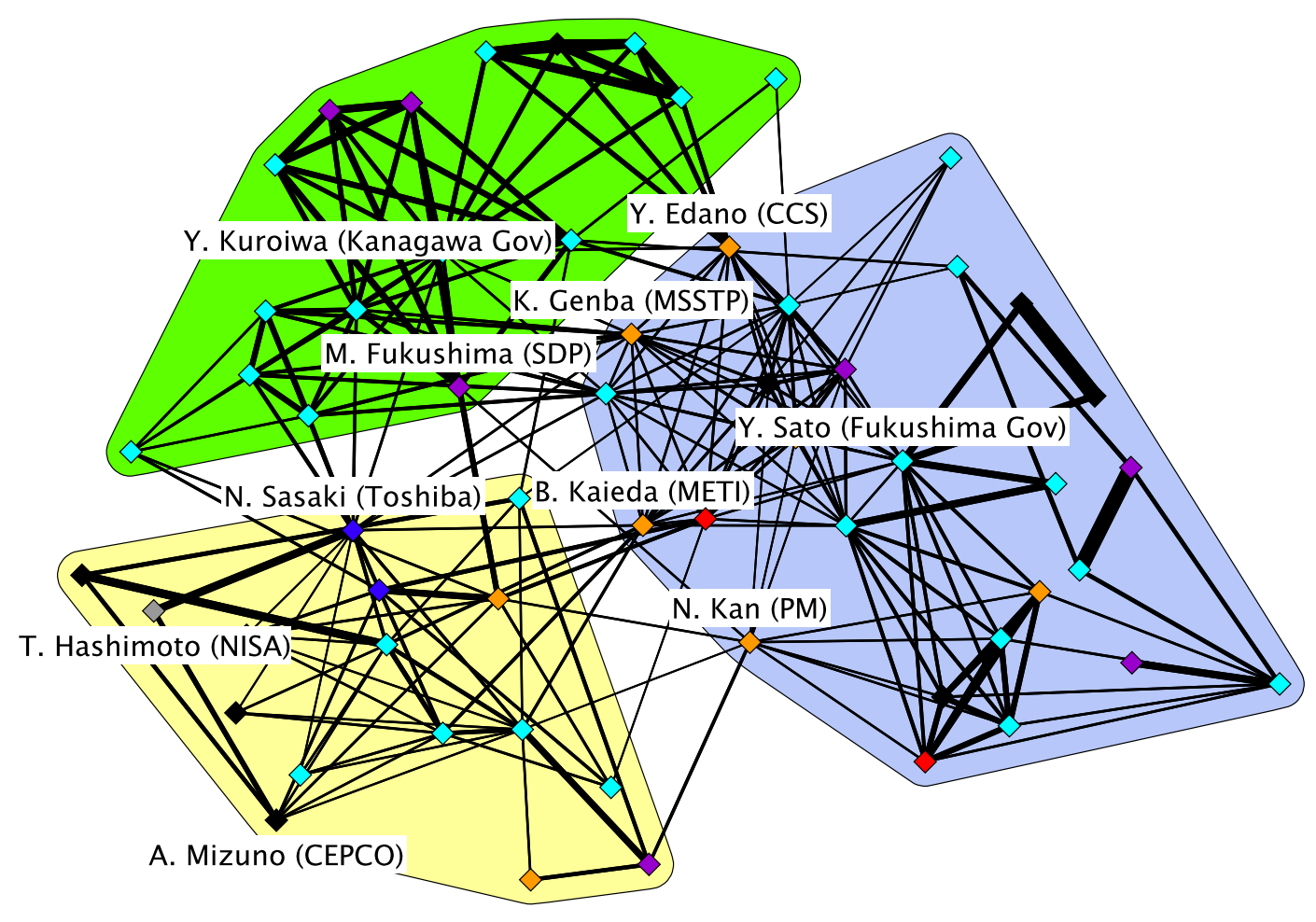

Figure 4. Normalized Actor Congruence Network, March 12, 2011-May 7, 2011 $(\Phi(w) 0.02, p=0.87)$

but open-ended review of Japan's nuclear power policy. The coalition included the Prime Minister and further members of the government, as well as numerous actors from subnational levels who had responded to the Fukushima accident by modifying their regulatory preferences regarding nuclear power. The "radical change coalition" (green), on the other side, advanced demands for a complete phase-out and called into question the restart of regularly inspected reactors. This coalition comprised 16 actors, among them governors and politicians from the parliamentary opposition.

As can be inferred from the discourse network depicted in Figure 4, the Fukushima crisis temporarily eroded the policy monopoly of the nuclear village and opened the floor to debate about the fundamentals of nuclear power policy. During the first two months after the accident, the unitary subsystem structure became modified into an adversarial one, with a number of policy communities pursuing different demands, proposals, and interests.

Figure 5 shows the actor congruence network for the subsequent period, covering the phase between May 8, 2011 and the resignation of the Kan administration (August 30, 2011). Similar to the immediate post-crisis discourse network, the graph contains three policy communities as detected by the GNA. Both the number of actors (161 in total) and degree of network polarization $(p=0.90)$ are higher than in the previous period, 


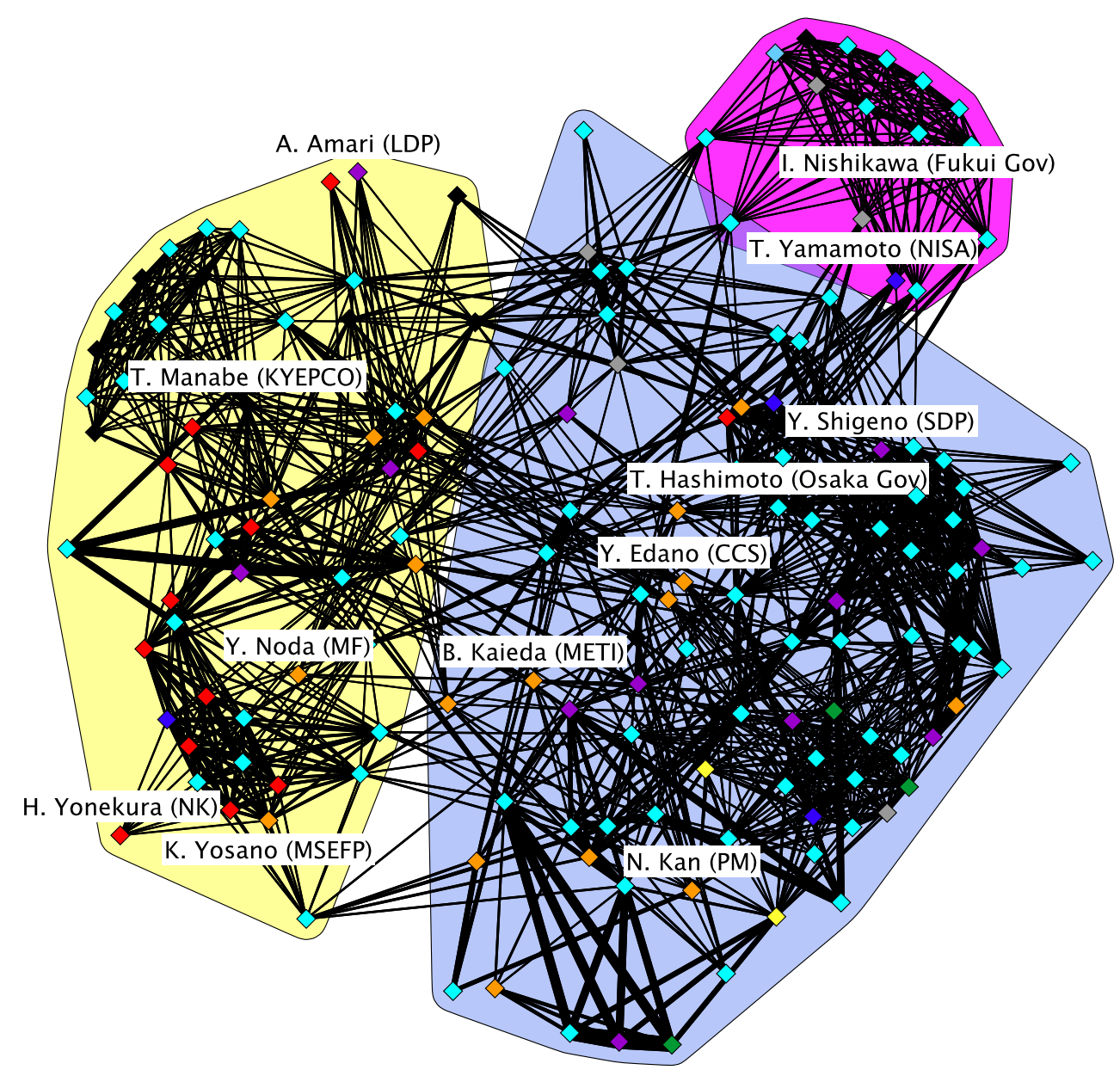

Figure 5. Normalized Actor Congruence Network, May 8, 2011-August 31, 2011 $(\Phi(w) 0.011, p=0.90)$

implying further fragmentation of the policy discourse.

The "BAU"-coalition (displayed on a yellow background) includes 55 actors who were bound together by a pro-nuclear policy image and their aspirations to save the nuclear industry and utilities from radical restructuring. In particular, actors like KYEPCO President T. Manabe and NK's Chairman H. Yonekura urged a rapid restart of nuclear plants and pointed to the crucial role of nuclear energy concerning Japan's economic viability. These claims were shared by a substantial number of sub-national politicians as well as business representatives and several members of government such as the Minister of Economic and Fiscal Policy (MSEFP), K. Yosano, and the Minister of Finance (MF), Y. Noda. Several nuclear proponents such as former LDP METI A. Amari engaged in "frame bridging" (Snow 2004) by connecting their opposition to a nuclear exit with the claim that renewable energies were not a viable alternative to nuclear power. A number of subsystem actors who were basically in favor of the nuclear 
option responded to the Fukushima stimulus by calling for some minor lessons to be learnt. Demanding a review of safety standards and temporary shutdowns in order to thoroughly assess the policy implications of the crisis, these principally pro-nuclear actors formed a separate policy community (purple background in Figure 5).

The coalition displayed on a blue background (89 actors) includes advocates of radical policy change as well as proponents of safety improvements (i.e., minor policy change), both of which promoted the image of nuclear power as hazardous. Whereas the radical change advocates primarily comprised actors from parliamentary opposition, the prefectural level and some NGOs, several ministers, and other members of the governing Democratic Party (DPJ) were anchored in the group of "safety advocates". The safety discourse centered mainly around the conducting of comprehensive safety assessments of Japan's reactors-socalled nuclear stress tests-which were announced by METI B. Kaieda on July 6 . By employing relatively strict safety standards based on tests designed by the European Union, they were meant to assess the plants' ability to withstand disasters of unanticipated severity. As restarting the regularly inspected NPPs was made conditional upon their successfully passing the stress tests, not a single inspected reactor was reconnected to the grid until July 2012. Whereas these developments deeply affected the Japanese economy, it needs to be noted that-being only temporary and not part of a general nuclear exit strategy-they do not represent a case of major policy change.

The Fukushima crisis thus shifted the structural setup of the subsystem from unitary to adversarial, with more and more subsystem actors voicing nuclear-skeptic claims after 3/11, but only a handful of high-ranking potential policy entrepreneurs-i.e., agents equipped with the capacity to construct a coherent and convincing policy image and to build a powerful coalition around their policy proposals (Mintrom and Vergari 1996, 423) - issued demands for more radical policy reactions. Having pushed forward the Hamaoka shutdown and testified that the Fukushima accident marked a watershed for nuclear power in Japan, Prime Minister N. Kan was certainly the most influential change agent after Fukushima. Kan came up with a plan to replace the NISA with a new independent regulatory body in May and announced a fundamental break with Japan's former nuclear path on July 13 . However, the Prime Minister encountered significant opposition from ministers and other high-level policymakers who acted as protectors of village interests, as is illustrated by the actor congruence network in Figure 5. In particular, Kan lost support for his nuclear policy from several factions of the Democratic Party, among which the Kaseikai faction (around MF Y. Noda) figured most prominently. After the Liberal Democrats had convinced about 80 DPJ rebels to support a no-confidence vote against Kan, he still managed to push through some substantial energy policy measures such as regulation supporting a feed-in-tariff remuneration system for the promotion of renewable energies (AlBadri 2013), but finally had to leave office without having prevailed in carrying through a nuclear exit policy. Employing Kingdon's (2010) MS metaphor, Kan was able to connect the problem stream (risk of nuclear accidents) with the policy 
stream (nuclear exit as a solution to the problem), but did not manage to couple the two with the politics stream due to the deep-seated dominance of the nuclear village.

Outlook: Revenge of the Village in a Polarized Subsystem

After the takeover by the Noda government the public discourse around nuclear power policy calmed down, but the configuration of the subsystem remained adversarial. The nuclear issue regained particular prominence in the second half of 2012 when the government endorsed a plan to phaseout nuclear power. However, the proposal being contested within and beyond the cabinet, Noda quickly backpedaled once Japan's three largest business associations released a joint statement in which they accused the government of having ignored their objections to the plans. In the weeks to come, the Prime Minister backed away from getting his fingers burned in the nuclear power policy arena once again. These developments signify a "major victory for the nuclear village" in that they entailed "kowtowing to the large business lobby Keidanren [...], a major pillar of the nuclear village", and other nuclear proponents (Kingston 2013, 505).

Nevertheless, the Fukushima accident triggered "continuing nuclear controversy" between the proponents and opponents of nuclear energy and an enduring polarization of the subsystem (Fam et al. 2014). While nuclear power had not been an issue of partisan cleavage prior to $3 / 11$, the election campaign in autumn 2012 saw the rise of several newly founded parties, most of which conveyed claims for a full nuclear phase- out. None of these parties, though, pursued a distinctly "green" agenda, and, due to their fragmentation, they "offered little unified antinuclear resistance, while economic and security issues reportedly determined the [election] outcome" (Kingston 2013, 509). Ending up in a landslide victory for the LDP, the elections did not institutionalize the discursive polarization but instead marked the return to power of the party that had for decades been in a cozy relationship with the nuclear industry and utilities. In order to regain economic strength, new Prime Minister S. Abe endorsed the construction of new NPPs and urged the restart of reactors currently off the grid, praising nuclear power as "the best and most cost-effective option" with regard to energy supply (Kingston 2013, 519). However, as increasingly nuclear-skeptical media coverage and drastically reduced public support for nuclear power (The Asahi Shimbun 2014) demonstrate, the Fukushima accident has created the first "anchors" for a radical policy shift by eroding the policy monopoly of the nuclear village and making alternative ideas and proposals available (Fam et al. 2014). It remains to be seen whether, when, and how these policy alternatives will materialize.

\section{Germany: From Bipolarization to Major Change}

Pre-Fukushima Polarization around the Exit from the Exit

$\mathrm{F}$ igure 6 shows the actor congruence network for the German nuclear power policy discourse between September 1, 2010 and March 11, 2011. 
The network includes 78 actors representing diverse institutional backgrounds, with most coming from NGOs, the state level (e.g., Minister-Presidents) and parliamentary opposition on the federal level. The relatively low network density value $(d=0.14)$ provides evidence of an adversarial pre-crisis subsystem setup, and the GNA more precisely illustrates the discursive bipolarization between supporters (blue background) and opponents (yellow background) of nuclear power.

The pre-Fukushima snapshot incorporates the discourse around the envisaged revision of the nuclear exit policy that was enacted 10 years earlier. Codifying the lifetime extension of 17 German reactors, the exit from the exit was finally adopted by the new conservative-liberal government on October 28, 2010. Because it fundamentally reversed the previous phase-out policy known as nuclear consensus and signified a "huge setback to ongoing efforts to transform the energy mix" (Jahn and Korolczuk 2012, 161), the decision was labeled a "radical policy shift" (Nullmeier and Dietz 2012, 88).

Besides conservative and liberal policymakers, pro-nuclear advocates included actors from the German states that host reactor sites and the operators of German nuclear plants such as RWE and E.ON. By depicting nuclear power as a safe technology that was necessary for building a bridge toward the era of renewable energies, the members of this dominant coalition called for the lifetime extension of reactors. In terms of coalition size, the pro-nuclear coalition was clearly outnumbered by the minority coalition consisting of nuclear opponents. Among the members of the anti-nuclear coalition were actors with diverse affiliations; in particular, policymakers from the Social Democrats (SPD), the Greens and the Left, as well as NGOs like Greenpeace and actors representing renewable energy interest groups such as the German Wind Energy Association (BWE). The numerical preponderance of the anti-nuclear coalition corresponded with the public mood: in September 2010, three fifths of the German population opposed the proposal for the lifetime extension (Forschungsgruppe Wahlen 2010). Moreover, the amendment to the Atomic Energy Act led to a massive decline in electoral support for the government coalition (Jahn and Korolczuk 2012, 161). Nevertheless, after the decision was taken, the nuclear power policy discourse markedly calmed down (see Figure 2).

\section{Nuclear Power Policy Discourse after Fukushima}

In contrast to the Japanese case, the German nuclear power policy subsystem witnessed a dramatic discursive outburst and immediate policy activism directly after 3/11 (see Figure 2). Three days after the Tohoku earthquake, the chancellor announced a three month moratorium on the lifetime extension, and less than 12 weeks after the beginning of the crisis the government decided to phase-out nuclear energy until 2022. This U-turn in German nuclear energy policymaking has been described as an "unexpected and sudden shift" (Huß 2015, 528), a "regime shift" (Strunz 2014, 155) and a "radical policy change" (Haunss, Dietz, and Nullmeier 2013; Jahn and Korolczuk 2012; Nullmeier and Dietz 2012). Proceeding from a historical-institutionalist perspective, Stefes $(2014,52)$, however, argues that "the meaning of the nuclear phase-out shifts" 


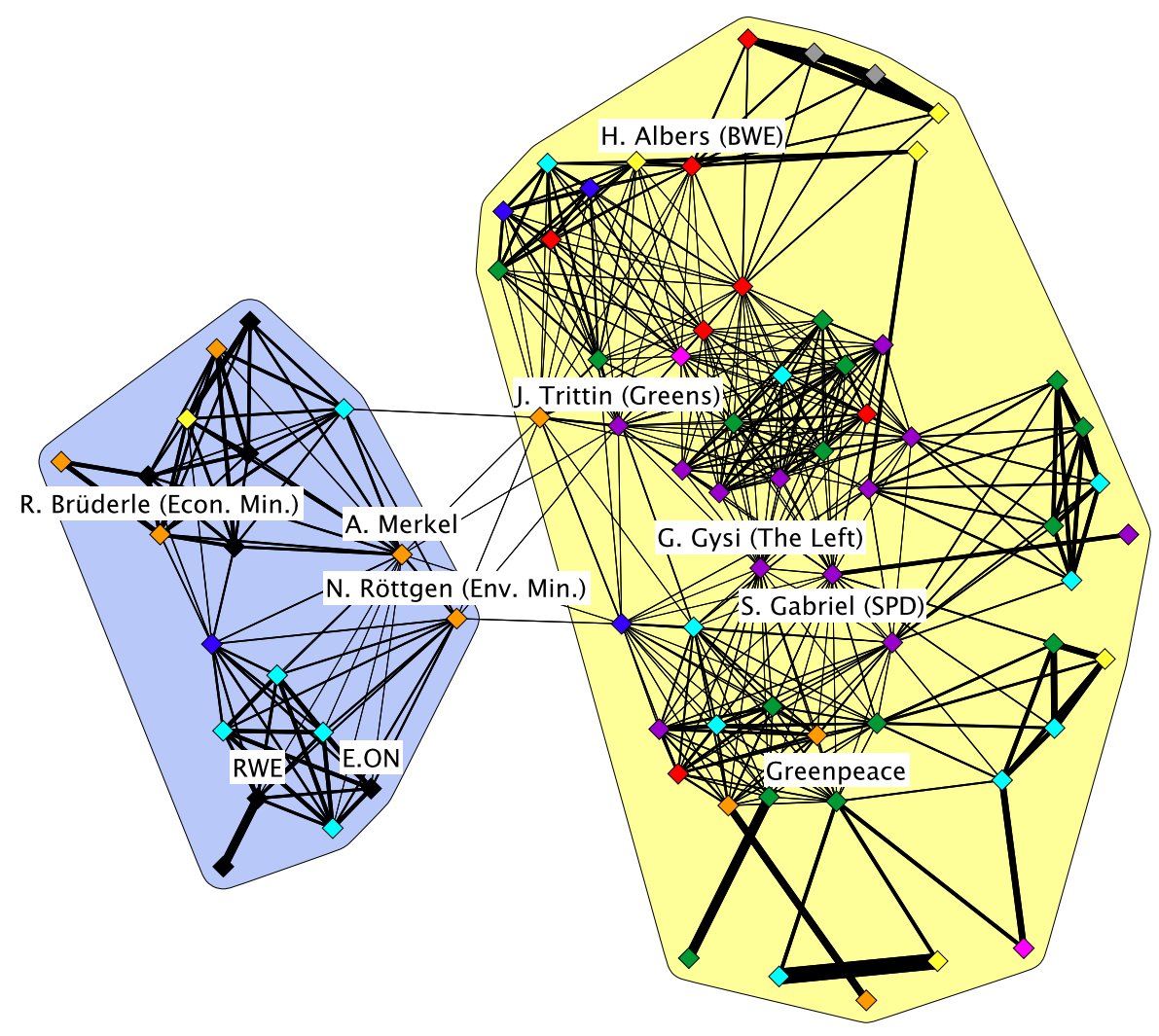

Figure 6. Normalized Actor Congruence Network, September 1, 2010-March 11, $2011(\Phi(w) 0.01, p=0.86)$.

Table 3. Nuclear Power Policy after Fukushima in Germany: Important Stages. Sources: Nullmeier and Dietz (2012) and newspaper articles from Süddeutsche Zeitung

\begin{tabular}{ll} 
March 14,2011 & The chancellor announces a three month moratorium on the lifetime extension. \\
\hline March 22,2011 & $\begin{array}{l}\text { The chancellor appoints the "Ethics Commission for a secure energy supply" in order } \\
\text { to review the technical and ethical aspects of NP. }\end{array}$ \\
\hline April 7,2011 & $\begin{array}{l}\text { The Council on Global Change presents a report that calls for a sustainable energy } \\
\text { system independent from nuclear power. }\end{array}$ \\
\hline May 17,2011 & $\begin{array}{l}\text { The Reactor Safety Commission presents its report on German NPPs. Accordingly, } \\
\text { domestic NPPs are more robust than Japanese ones, but gaps remain in the protection } \\
\text { against terror attacks and plane crashes. }\end{array}$ \\
\hline May 30,2011 & $\begin{array}{l}\text { The Ethics Commission recommends to phase-out NP within a decade. The cabinet } \\
\text { adopts the Commission's recommendation. }\end{array}$ \\
\hline June 30,2011 & $\begin{array}{l}\text { The Bundestag passes the phase-out law. Hence, the NPPs will be disconnected in } \\
\text { stages until 2022. }\end{array}$
\end{tabular}


if a longer time span is considered, since it represents "just one component" of a "comprehensive policy change" known as Energiewende ${ }^{7}$. Nevertheless, after the lifetime extension reopened the door to the nuclear option and "revived the battle between opponents and proponents of nuclear energy" (Jahn and Korolczuk $2012,161)$, the decision to permanently shut down all NPPs by 2022 signified a change in the policy core aspects of the German nuclear power program-i.e., a major policy change that "has made a return of nuclear energy in Germany highly unlikely" (Stefes 2014, 66). Given the relatively strong commitment to nuclear power of conservatives and liberals that had just recently materialized with regard to the lifetime extension, the unchanged composition of the government and the geographical distance from Japan, how can this major change-arguably the most far-reaching response to the Fukushima accident of any country-be explained? Tracing the evolution of the subsystem using discourse network analysis helps to shed light on the processes that brought about this exit from the exit from the exit.

Figure 7 depicts how the configuration of discourse coalitions developed within the first nine weeks after the Fukushima accident. The period ends with the publication of the Reactor Safety Commission's report on German NPPs on May 17 (see Table 3). During this time lapse, the network density value $(d=$ 0.07 ) was even lower than prior to $3 / 11$, indicating strong polarization of the subsystem. By detecting four distinct policy communities, the GNA points in the same direction. The high level of fragmentation of the policy discourse was primarily due to the emergence of a heterogeneous set of policy proposals in response to Fukushima. An immediate nuclear exit was demanded by the actors pertaining to the cluster displayed on the green background representing "green" interest groups such as the Renewable Energies Association (BEE) and NGOs, among others. Being decisively anti-nuclear as well, the members of the community indicated on the red background made use of different argumentative frames. Instead of demanding a quick phase-out, they primarily pointed toward the potentially devastating impacts of nuclear accidents, leaving the question of what policy reactions to Fukushima should look like open. Arguing on a more general level, this coalition comprised several scientists and NGO representatives. Calling for a quick revision of the lifetime extension decided upon in 2010, the coalition indicated on the yellow background contained lots of actors from the pre-crisis minority coalition such as parliamentary opposition members and policymakers from the state level. These actors were bound together by their preference for investment into renewable energies and the desire for a decentralizing transformation of the German power supply system. In terms of group size, the coalition on the light blue background clearly outnumbers the other clusters. It contained both pro-nuclear and (moderate) change advocates, thus including members of the previously dominant coalition who constantly emphasized the image of nuclear power as a safe technology (such as RWE's CEO, J. Grossmann), and members of the previous minority coalition (such as S. Gabriel, chairman of the SPD). Given the strong pre-crisis cleavage, the composition of this coalition seems counter-intuitive and needs some clarification. Agreeing that a disaster of such a magnitude was exceed- 


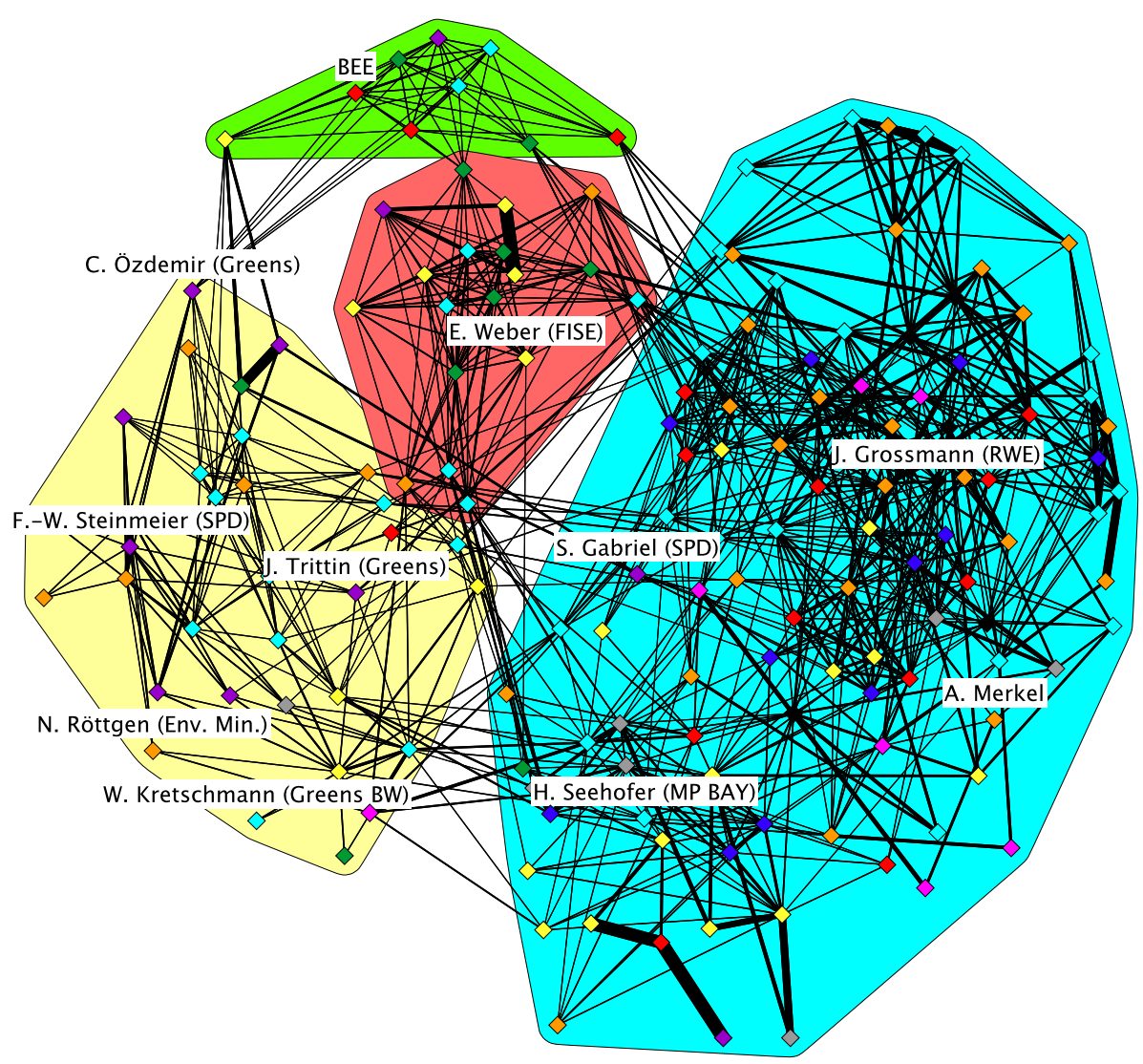

Figure 7. Normalized Actor Congruence Network, March 12, 2011-May 18, 2011 $(\Phi(w) 0.012, p=0.93)$

ingly unlikely to happen in Germany and thus having a multitude of discursive ties to proponents of nuclear power, some pro-nuclear advocates from the governing parties stated that $3 / 11$ had profoundly altered their perception of the risks associated with nuclear power. The propagation of demands for a corresponding policy reaction was contingent on a limited number of key individuals that revised their assessment of nuclear power in light of the Fukushima crisis. Among these actors was the chancellor, who declared that the

"Incredible events in Japan teach us that something that was considered impossible by all scientific standards finally became possible. [...] If [...] the seemingly impossible becomes possible [...], then this changes the situation" (Merkel 2011, author's translation).

After having belonged to the dominant coalition that had reversed the nuclear consensus in 2010 (see Figure 6), A. Merkel announced the moratorium quickly after the quake, but nevertheless did not intend to react prematurely to the crisis and instead opposed a quick nucle- 
ar exit. Through being aligned with both change and status quo players at the same time, Merkel and other cabinet members built discursive "bridges" between the different camps. By affirming the high safety standards of German NPPs while at the same time enacting the moratorium and shifting venues by installing an expert commission to review the technical and ethical aspects of nuclear energy in light of the Fukushima accident (the so-called Ethics Commission), the government "hedged" nuclear utilities and satisfied public demands for legislative action. In contrast to the theoretical expectations developed above, however, the former minority coalition did not directly contribute to the meltdown of the pro-nuclear policy image from the very beginning, but instead pulled its punches due to the severity of the nuclear disaster. The deep-seated subsystem polarization and the constellation of nuclear-skeptic attitudes and arguments that had been put forward by the minority coalition for decades, however, indirectly took effect through extensive and vibrant media coverage of the Fukushima incident, which the Merkel cabinet rapidly reacted to by signaling that "something needs to be changed".

Remember that, according to the ACF, crises can induce major policy change in a policy subsystem by altering policy beliefs, modifying the power of coalitions, and relocating coalition resources (Weible, Sabatier, and McQueen 2009, 124). Whereas it is debatable whether Fukushima actually changed the beliefs of dominant coalition members (or whether the communication of changed risk perceptions can be considered pure rhetoric), and whereas the-at least formal-balance of power was not subject to shifts in the immediate wake of Fukushima, the credibility resources of the dominant coalition regarding its policy image of cheap and safe nuclear power were depleted, providing significant incentive for the government to change track after $3 / 11$.

The last actor congruence network (Figure 8) sheds light on the subsystem structure between May 19 and July 1. According to the network density $(d=0.17)$ and the GNA, the subsystem polarization receded until the Bundestag adopted the decision to phaseout nuclear power (June 30). During this period, the "transition phase" during which various actors had expressed claims both revealing a favorable stance toward nuclear power and demands for change came to an end. In particular, the exit claim could become hegemonic because the proponents of the "business-as-usual"-policy neither succeeded in articulating a coherent pro-nuclear policy image nor took up central positions in the discourse network (see also Haunss, Dietz, and Nullmeier 2013, 313). After fierce struggles and significant political polarization during the first onehand-a-half years of the conservativeliberal government in office, a "consensus atmosphere in environmental policy making" (Huß 2014, 431) emerged, and the nuclear power policy subsystem converged to a unitary setup, highlighting the collapse of the previously dominant coalition.

Given the pre-Fukushima preference among dominant coalition members for a lifetime extension and their claim that nuclear power was a safe technology, the approval for the nuclear exit strategy by a large majority of parliamentarians can be seen as the endpoint of a positive feedback process that worked its 


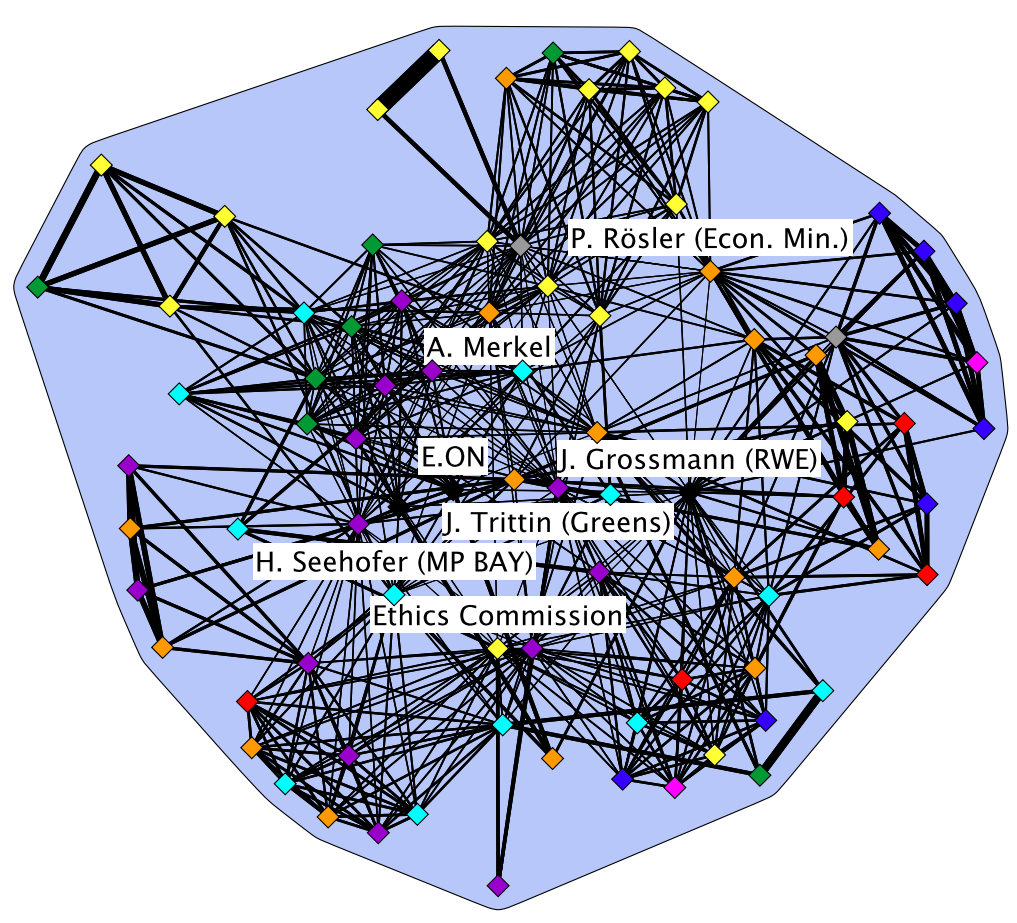

Figure 8. Normalized Actor Congruence Network, May 19, 2011-July 1, $2011(\Phi(w)$ $0.015, p=0.83)$.

way through the post-crisis discourse (see Baumgartner and Jones 2009, 16). The propagation of pro-change claims through the network resulted in a meltdown of the pre-crisis policy when the Bundestag voted in favor of the irreversible shutdown of all remaining German NPPs until 2022. After the amendment was passed, nuclear power policy discourse significantly calmed down (see Figure 2).

\section{Comparing Policy Divergence in Japan and Germany}

$\mathrm{I}$ $\mathrm{n}$ order to systematically compare subsystem setups based on the discursive interaction of policy elites among both cases under scrutiny, the enormous complexity of policy discourse must be scaled down to simplifying yet meaningful measures. Two ways to compare the subsystem reconfigurations of both cases over time are network density $(d)$ and the Girvan-Newman clustering algorithm. Whereas network density "can be interpreted as a measure of overall agreement between the actors" in a network (Leifeld and Haunss 2012, 399), its complementary value $(1-d)$ can be interpreted as network polarization. Likewise, the number of "policy communities" detected by GNA should increase with disagreement between the actors.

Figure 9 compares Japan and Germany with regard to the evolution of discursive polarization (left panel) and number of policy communities (right panel) over three measurement periods 

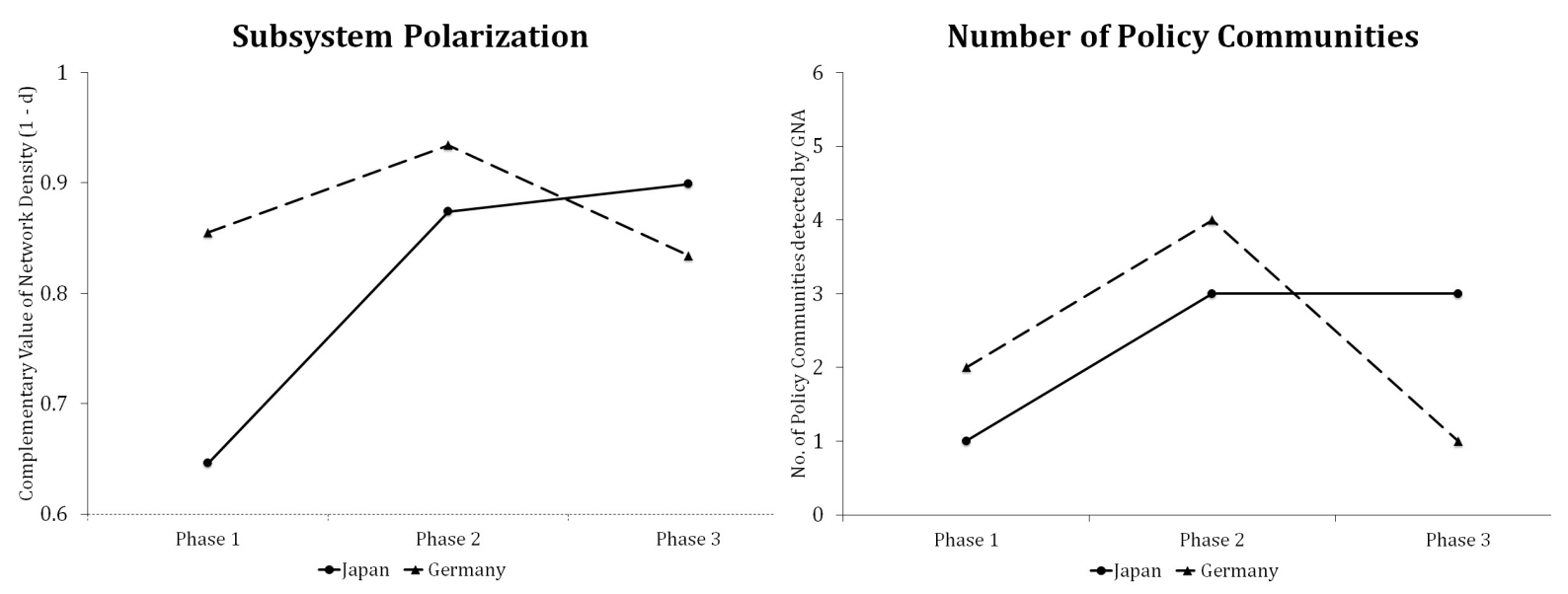

Figure 9. Subsystem polarization and number of policy communities in Japan and Germany before (phase 1) and after Fukushima (phases 2 and 3). Notes: Subsystem polarization is measured by the complementary value of network density (i.e., $1-d$ ). Higher values correspond to higher discursive polarization. Policy communities are detected with the Girvan-Newman algorithm (Girvan and Newman 2002; see actor congruence networks above for visualization). The phases correspond to the time frames of actor congruence networks

around Fukushima. Both methods yield comparable results, confirming both the rationale behind the case selection and several of the theoretical expectations. With regard to the former, the Japanese pre-Fukushima discourse network featured a relatively low polarization value of 0.65 and was comprised of a single policy community, hence corroborating its classification as unitary. The German discourse network prior to $3 / 11$, on the other hand, was much more polarized ( $p_{1}$ $=0.86$ ), with two policy communities detected by the GNA, highlighting bipolarization between nuclear proponents and opponents.

In Japan, however, the Fukushima crisis had an enduring effect on the subsystem structure by breaking up the policy monopoly of the nuclear village.
This monopoly was based on the previously unchallenged policy image of safe, cheap, and reliable nuclear energy. The longitudinal development of the subsystem between June 2010 and August 2011 demonstrates a transition away from unitary default to an adversarial setup, with the Fukushima crisis acting as a catalyst for emerging polarization. This corroborates the expectation that crises can lead to the emergence of new minority coalitions in an initially unitary subsystem (see Nohrstedt and Weible 2010, 23). Because the nuclear village regained discursive strength and managed to keep and reinstall its members in positions of formal (and informal) authority, the translation of newly emergent policy alternatives into a major policy shift was blocked.

In Germany, as was the case in 
Japan, the Fukushima crisis triggered a temporary increase in subsystem polarization, but gave way to a convergence of policy claims thereafter (as revealed by the decreasing values of $p$ and GNA from phase 2 to 3 ). Since the nuclear hostile policy image employed by the previous minority coalition captured almost all subsystem stakeholders after $3 / 11$, the dominant coalition collapsed, leading to a less polarized configuration. Because most dominant coalition members could not resist the propagation of pro-change proposals and demands after $3 / 11$, a major policy shift was finally decided upon in a consensual atmosphere. These findings corroborate Leifeld's (2013) conjecture that polarization of two opposing coalitions might be a necessary condition for major policy change to occur, and they correspond to Nohrstedt and Weible's $(2010,23)$ expectations that under crisis conditions, "one coalition will collapse, creating one dominant coalition and the emergence of a unitary subsystem".

\section{Conclusion}

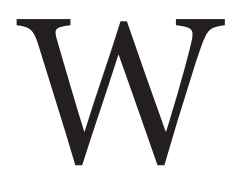

hy would a country that is located 6,000 miles away from a nuclear accident react by adjusting its nuclear energy policy, while a country that is directly affected keeps assigning nuclear power a major role in its power supply portfolio? Whereas previous studies have attributed major policy change in Germany to some kind of "exceptionalism" (Jahn and Korolczuk 2012) and policy stability in Japan to the nation's "incapability to learn" (Kido 2013, 181), this contribution links theoretical arguments from the policy process literature with discourse network analysis in order to give of a more finegrained answer to this question. Having assessed policy subsystem structures based on an actor-centered approach, the degree of pre-crisis polarization of a policy subsystem can be substantiated as an important condition when it comes to explaining variation in crisis-induced policy reactions among different jurisdictions. Adversarial subsystems with relatively high degrees of polarization are characterized by pre-existing policy conflicts and availability of alternative ideas and policy proposals. The likelihood of major policy change increases if change players successfully provoke bandwagon effects (Nadeau, Cloutier, and Guay 1993), which can lead to the collapse of the dominant coalition's policy image, as was shown with nuclear power policy in Germany after 3/11. Major changes after crises, however, do not materialize out of the blue. In unitary subsystems which are captured by a single interest, "anchors" of change first have to be established before a translation into policy shifts can eventually follow. The Japanese policy reaction to the Fukushima accident shows that a single incident is not sufficient to produce major change. Because processes of perceptual filtering appeared in terms of "solidarity and group-think" as well as the marginalization of dissenting views within the nuclear village (Kingston 2012, 2), a major policy shift was effectively inhibited. Thus, whereas the severity of an event alone seems to be a poor predictor of policy reactions, "the specific setup of a policy subsystem" has much more direct "implications for policymaking dynamics in the wake of crisis" (Nohrstedt and Weible 2010, 13). 


\section{Limitations and Avenues for Fu- ture Research}

\section{Alternative Explanations}

$\mathrm{T}$ he topographic comparison of policy discourses around the Fukushima crisis in Japan and Germany yields important insights, but it is necessary to put the findings into perspective. The structural setup of policy subsystems has been theorized to be a relevant factor when it comes to explaining variations in post-crisis policymaking, and the empirical analysis of this contribution demonstrates that unitary and adversarial subsystems indeed followed divergent logics after the outbreak of the Fukushima crisis. However, by putting the discursive interaction of policy elites under the microscope, the risk of underemphasizing alternative explanations for why major policy change happened in Germany but did not happen in Japan after Fukushima is encountered (see George and Bennett 2005, 90-92). For example, according to Davies (2011, 1963), Germany was in a unique position to make its phase-out choice "only because of its surging renewable energy production and because [...] it boasted substantial excess generation capacity". Whereas countries like Japan or, for example, Great Britain (see Wittneben 2012) did indeed not have alternatives to nuclear power readily available, the same pertains to Switzerland that followed suit Germany in phasing out nuclear power in the medium term (Siegrist, Sütterlin, and Keller 2014). Others argue that imminent elections in three German states and low approval ratings simply put pressure on the government to revise its pro-nuclear stance (Jahn and Korolczuk 2012; Wit- tneben 2012; see also Haunss, Dietz, and Nullmeier 2013 for a competing view).

However, both the differences in energy supply systems and in partisan competition, as well as explanations based on Germany's history of bold nuclear resistance (Wittneben 2012, 2) or Japan's history of institutionalized regulatory capture (Fam et al. 2014; Kingston 2012), are-to some extent-incorporated into historically shaped subsystem structures and are thus reflected in the discourse networks: Germany's pre-Fukushima anti-nuclear minority coalition represented, among others, the interests of the renewable energy industry, and the subsystem polarization was the result of long-standing opposition to nuclear power and the sharp partisan divide that emerged in the 1980s. The unitary subsystem setup of pre-Fukushima Japan, on the other hand, can be traced back to the policy monopoly of the nuclear village, the negligible role played by renewable energies in Japan's pre-crisis energy portfolio (see Hünteler, Schmidt, and Kanie 2012) and the absence of a partisan cleavage over the nuclear issue. Nevertheless, applying strict causal logic, discourse network analysis alone is not sufficient to explain the cases based on the theoretical propositions. In order to test more rigorously and for a wider range of cases whether subsystem polarization is indeed a necessary but not sufficient condition for major crisis-induced policy change and to examine the influence of alternative explanatory factors and causal configurations in post-crisis policymaking, a combination of discourse network analysis with both qualitative comparative analysis (QCA; see Schneider and Wagemann 2012) and process tracing techniques is suggested as an innovative approach. Moreover, 
the linkage between crises and policy reactions should be explored for further types of subsystems, such as collaborative ones (see Weible 2008, 625).

\section{Methodological and Conceptual Challenges}

The application of discourse network analysis involves methodological challenges that need to be noted. In contrast to other approaches of social network analysis, the set of actors usually varies from one measurement period to the next, which hampers the longitudinal comparability of discourse networks. In line with previous research (Leifeld and Haunss 2012), this study nevertheless employs global network measures in order to assess the dynamic development of discourse networks, but the corresponding depictions should be interpreted with caution (see Figure 9). Moreover, the choice of high-quality newspapers does not guarantee that all relevant actors are captured, due to potentially unequal access and visibility in different news media. Consequently, the concrete choice of newspapers used in this study might be confronted with the critique of being biased: whereas Yomiuri Shimbun is judged as leaning toward a conservative stance (Feldman 1994, 11) and having a history of nuclear energy promotion (Kido 2013, 181-182), Süddeutsche Zeitung is described as left-liberal or "moderate left" (Brocchi 2007). In spite of this, media norms and practices such as the "balance norm", which "is provided by quoting spokespersons with competing views" (Gamson and Modigliani 1989, 8) and ignoring (i.e., not coding) comments from individual journalists should, at least, mitigate the bias. In future studies, assessment of subsystem structures by discourse network analysis could be improved by drawing on additional sources such as interviews and combining the method with other approaches of social network analysis.

As was shown in this contribution, the ACF can be fruitfully combined with other theoretical perspectives on the policy process such as PE theory and the MS approach, and future research should spell out and integrate more thoroughly the complementarities and conceptual overlap between these approaches. For example, the notions of unitary policy subsystems (ACF) and successful policy monopolies (PE) are conceptually very close, and a closer focus on issues of timing and agenda setting (MS, PE) can help to improve the ACF in understanding how advocacy coalitions coordinate especially under crisis conditions. Therefore, following Schlager's $(2007,317)$ claim that the discussed theories of the policy process "probably belong under a single roof"; conceptual work that brings together these approaches is encouraged.

\section{Notes}

${ }^{1}$ Quite importantly, however, a "minority coalition" might well represent a societal majority at any given point in time. The conceptual difference between dominant and minority coalitions lies solely in the exclusive capacity of the former to enact laws. ${ }^{2}$ An advantage of looking at political discourse through the lens of political claims analysis (Koopmans and Statham 1999) is that this approach remains theoretically agnostic with regard to actor's motivations. Political claims, as conceptualized in this contribution, not only cover "demands, criticisms, or proposals" but they can also include material interests, ideas, beliefs, preferences, or whatever motivates agents. It therefore makes sense to rely on the umbrella construct of the "political claim" if more general patterns of discursive interaction rather than the identification of an actor's motivation is the core research interest. 
${ }^{3}$ The manual including some coding examples is contained in the online supplement. ${ }^{4}$ Previous applications of discourse network analysis do not sufficiently acknowledge that the straightforward expression of claims in political discourse is rare. In fact, a clear statement such as "nuclear power is a risky technology and therefore we should abandon it" (-a fictitious example) was seldom made in either the Japanese or the German discourse. Instead, the discourses in both countries were characterized by allusions, metaphorical statements, or cross references that require background knowledge. As an illustration, consider the following example from the Süddeutsche Zeitung: "Instead of taking the nuclear crutches Krümmel and Brunsbüttel finally from the network, Vattenfall prefers playing with risk because of tight budgets', said the nuclear policy spokesperson of the Green Party, Sylvia Kotting-Uhl" [translated by the author]. This typical example of a statement was coded in the following way: date: September 21, 2010, person: Sylvia Kotting-Uhl, organization: Greens; claim: "NP is a highrisk technology", agreement: yes. By design, this method of coding does not preserve the specific assertion in a direct sense, but it makes an abstraction that is still congruent with the sense of the message while at the same time allowing related statements to be subsumed under the same claim.

${ }^{5} \mathrm{~A}$ list of the articles which were analyzed is available upon request.

${ }^{6}$ There is one exception to the last color code: Vattenfall does not run NPPs, but represents one of the "big four" oligopolistic utilities in Germany.

${ }^{7}$ In a similar vein, Huß $(2014,439)$ contends that Fukushima engendered "simply a surprisingly fast switch back to a slightly tightened status quo ante 2010”.

\section{References}

Al-Badri, Dominic. 2013. "Unity and Fragmentation: Japanese Politics Post-Fukushima." In After the Great East Japan Earthquake-Political and Policy Change in Post-Fukushima Japan, eds. Dominic AlBadri, and Gijs Berends. Copenhagen: NIAS Press, 37-66.

Alink, Fleur, Arjen Boin, and Paul 't Hart. 2001. "Institutional Crises and Reforms in Policy Sectors: The Case of Asylum Policy in Europe." Journal of European Public Policy 8 (2): $286-306$.

Anderson, Charles W. 1978. "The Logic of Public Problems: Evaluation in Comparative Policy Research." In Comparing Public Policies: New concepts and methods, ed. Douglas Ashford. Thousand Oaks, CA: Sage, 19-41.

Barranco, José, and Dominique Wisler. 1999. "Validity and Systematicity of Newspaper Data in Event Analysis." European Sociological Review 15 (3): 301-322.

Baumgartner, Frank R., and Bryan D. Jones. 2009. Agendas and Instability in American Politics. Chicago: University of Chicago Press.

Baumgartner, Frank R., Bryan D. Jones, and Peter B. Mortensen. 2014. "Punctuated Equilibrium Theory: Explaining Stability and Change in Public Policymaking." In Theories of the Policy Process, eds. Paul A. Sabatier, and Christopher M. Weible. Boulder, CO: Westview Press, 59-103.

Birkland, Thomas A. 2006. Lessons of Disaster-Policy Change after Catastrophic Events. Washington, DC: Georgetown University Press. 
Blumer, Herbert. 1971. "Social Problems as Collective Behavior." Social Problems 18 (3): 298-306.

Boin, Arjen, Paul 't Hart, and Allan McConnell. 2009. "Crisis Exploitation: Political and Policy Impacts of Framing Contests." Journal of European Public Policy 16 (1): 81-106.

Brandes, Ulrik, and Christian Pich. 2009. "An Experimental Study on Distance-Based Graph Drawing." In Proceedings of the 16th International Symposium on Graph Drawing. Berlin: Springer, 218-229.

Brandes, Ulrik, and Dorothea Wagner. 2004. "Analysis and Visualization of Social Networks." In Graph Drawing Software, eds. Michael Jünger, and Petra Mutzel. Berlin Heidelberg: Springer, 321-340.

Brocchi, Davide. 2007. "Die Presse in Deutschland." In Media e società in Italia e Germania, ed. MediaClub Germania. Köln: MediaClub Germania, 22-31.

Coleman, James S. 1990. Foundations of Social Theory. Cambridge, Massachusetts, and London: The Belknap Press of Harvard University Press.

Colignon, Richard A., and Chikako Usui. 2003. Amakudari: The Hidden Fabric of Japan's Economy. Ithaca, NY: Cornell University Press.

Davies, Lincoln L. 2011. "Beyond Fukushima: Disasters, Nuclear Energy, and Energy Law." Brigham Young University Law Review 2011: 1937-1989.

Dryzek, John S. 1997. The Politics of the Earth: Environmental Discourses. New York: Oxford University Press.
Dudley, Geoffrey. 2007. "Individuals and the Dynamics of Policy Learning: The Case of the Third Battle of Newbury." Public Administration 85 (2): 405-428.

Fam, Shun D., Jieru Xiong, Gordon Xiong, Ding L. Yong, and Daniel Ng. 2014. "Post-Fukushima Japan: The Continuing Nuclear Controversy." Energy Policy 68: 199205.

Feldman, Ofer. 1994. Politics and the News Media in Japan. Ann Arbor: University of Michigan Press.

Festinger, Leon. 1985. A Theory of Cognitive Dissonance. Stanford, CA: Stanford University Press.

Forschungsgruppe Wahlen. 2010. "Mehrheit gegen längere Laufzeiten von Atomkraftwerken." http://www.forschungsgruppe.de/ Umfragen/Politbarometer/Archiv/ (July 26, 2015).

Gamson, William A., and Andre Modigliani. 1989. "Media Discourse and Public Opinion on Nuclear Power: A Constructionist Approach." American Journal of Sociology 95 (1): 1-37.

Geddes, Barbara. 1990. "How the Cases You Choose Affect the Answers You Get: Selection Bias in Comparative Politics." Political Analysis 2: 131-152.

George, Alexander, and Andrew Bennett. 2005. Case Studies and Theory Development in the Social Sciences. Cambridge: MIT Press.

George, Alexander L., and Timothy J. McKeown. 1985. "Case Studies and Theories of Organizational Decision Making." Advances in Information Processing in Organizations 2: 21-58. 
Girvan, Michelle, and Mark E.J. Newman. 2002. "Community Structure in Social and Biological Networks." Proceedings of the $\mathrm{Na}$ tional Academy of Sciences 99 (12): 78217826.

Glaser, Alexander. 2012. "From Brokdorf to Fukushima: The Long Journey to Nuclear Phase-Out." Bulletin of the Atomic Scientists 68 (10): 10-21.

Hajer, Maarten A. 1993. "Discourse Coalitions and the Institutionalization of Practice: The Case of Acid Rain in Britain." In The argumentative turn in policy analysis and planning, eds. Frank Fischer, and John Forester. Durham, NC: Duke University Press, 43-76.

Hajer, Maarten A. 1995. The Politics of Environmental Discourse: Ecological Modernization and the Policy Process. New York: Oxford University Press.

Hall, Peter A. 1993. "Policy Paradigms, Social Learning, and the State-The Case of Economic Policymaking in Britain." Comparative Politics 25 (3): 275-296.

Hanschmann, Raffael. 2015. "The Crisis-Induced Polarisation of EU Environmental Policy-Making." Presented at International Conference on Public Policy, Milan.

Haunss, Sebastian, Matthias Dietz, and Frank Nullmeier. 2013. "Der Ausstieg aus der Atomenergie." Zeitschrift für Diskursforschung (3): 288-315.

Howlett, Michael, and M. Ramesh. 1998. "Policy Subsystem Configurations and Policy Change: Operationalizing the Postpositivist Analysis of the Politics of the Policy Process." The Policy Studies Journal 26 (3): 466-481.
Hünteler, Jörn, Tobias S. Schmidt, and Norichika Kanie. 2012. "Japan's Post-Fukushima Challenge - Implications from the German Experience on Renewable Energy Policy." Energy Policy 45: 6-11.

Hurka, Steffen, and Kerstin Nebel. 2013. "Framing and Policy Change after Shooting Rampages: a Comparative Analysis of Discourse Networks." Journal of European Public Policy 20 (3): 390-406.

Huß, Christian. 2014. "Energy Transition by Conviction or by Surprise? Environmental Policy from 2009 to 2013." German Politics 23 (4): 430-445.

Huß, Christian. 2015. "Durch Fukushima zum neuen Konsens? Die Umweltpolitik von 2009 bis 2013." In Politik im Schatten der Krise-Eine Bilanz der Regierung Merkel 2009-2013, eds. Reimut Zohlnhöfer, and Thomas Saalfeld. Wiesbaden: Springer VS, 521-554.

Jahn, Detlef, and Sebastian Korolczuk. 2012. "German exceptionalism: the End of Nuclear Energy in Germany!” Environmental Politics 21 (1): 159-164.

Janning, Frank, Philip Leifeld, Thomas Malang, and Volker Schneider. 2009. "Diskursnetzwerkanalyse. Überlegungen zur Theoriebildung und Methodik." In Politiknetzwerke. Modelle, Anwendungen und Visualisierungen, eds. Volker Schneider, Frank Janning, Philip Leifeld, and Thomas Malang. Wiesbaden: VS Verlag für Sozialwissenschaften, 59-92.

Jenkins-Smith, Hank C., Daniel Nohrstedt, Christopher Weible, and Paul A. Sabatier. 2014. "The Advocacy Coalition Framework: Foundations, Evolution, and Ongoing Research." In Theories of the Policy Process, 
eds. Paul A. Sabatier, and Christopher M. Weible. Boulder, CO: Westview Press, 183224.

Kido, Eiichi. 2013. "Wohin treibt Japan? Lernunfähige Nation?” In Fukushima-Die Katastrophe und ihre Folgen, eds. György Széll, and Roland Czada. Frankfurt: Peter Lang $\mathrm{GmbH}, 181-184$.

Kingdon, John W. 2010. Agendas, Alternatives, and Public Policies, Second Edition. London: Pearson.

Kingston, Jeff. 2012. "Japan's Nuclear Village." Asia-Pacific Journal 10 (1).

Kingston, Jeff. 2013. "Nuclear Power Politics in Japan, 2011-2013." Asian Perspective 37: 501-521.

Koch, Matthias. 2001. "Neubewertung der Kernenergie in Japan zu Beginn des 21. Jahrhunderts?" In Wohnen in Japan: Markt, Lebensformen, Nachbarschaft, eds. Harald Conrad, and Sven Saaler. München: iudicium Verlag, 373-410.

Koopmans, Ruud, and Paul Statham. 1999. "Political Claims Analysis: Integrating Protest Event and Political Discourse Approaches." Mobilization 4 (2): 203-222.

Laumann, Edward O., Joseph Galaskiewicz, and Peter Marsden. 1983. "The Boundary Specification Problem in Social Network Analysis." In Applied Network Analysis, eds. Ronald Burt, and Michael Minor, Beverly Hills, CA: Sage Publications, 18-34.

Lehmbruch, Gerhard. 1995. "Ressortautonomie und die Konstitution sektoraler Politiknetzwerke-Administrative Interessenvermittlung in Japan." In Die Reformfähigkeit von Industriegesellschaften, eds. Karl- heinz Bentele, Bernd Reissert, and Ronald Schettkat. Frankfurt/New York: Campus, 64-100.

Leifeld, Philip. 2009. "Die Untersuchung von Diskursnetzwerken mit dem Discourse Network Analyzer (DNA)." In Politiknetzwerke. Modelle, Anwendungen und Visualisierungen, eds. Volker Schneider, Frank Janning, Philip Leifeld, and Thomas Malang. Wiesbaden: VS Verlag für Sozialwissenschaften, 391-406.

Leifeld, Philip. 2010. "Political Discourse Networks-The Missing Link in the Study of Policy-Oriented Discourse." Presented at the ECPR Joint Sessions of Workshops, Münster.

Leifeld, Philip. 2011. "Discourse Networks and German Pension Politics." PhD dissertation, University of Konstanz.

Leifeld, Philip. 2013. "Reconceptualizing Major Policy Change in the Advocacy Coalition Framework: A Discourse Network Analysis of German Pension Politics." The Policy Studies Journal 41 (1): 169-198.

Leifeld, Philip, and Sebastian Haunss. 2012. "Political Discourse Networks and the Conflict over Software Patents." European Journal of Political Research 51: 382-409.

Merkel, Angela. 2011. Regierungserklärung von Bundeskanzlerin Dr. Angela Merkel zur aktuellen Lage in Japan vor dem Deutschen Bundestag am 17. März 2011 in Berlin. Bulletin der Bundesregierung 27 (1).

Mintrom, Michael, and Sandra Vergari. 1996. "Advocacy Coalitions, Policy Entrepreneurs, and Policy Change." The Policy Studies Journal 24 (3): 420-434. 
Nadeau, Richard, Edouard Cloutier, and Jean-Herman Guay. 1993. "New Evidence About the Existence of a Bandwagon Effect in the Opinion Formation Process." International Political Science Review 14 (2): 203213.

Nohrstedt, Daniel. 2007. "Crisis and policy reformcraft: Advocacy Coalitions and Crisis-Induced Change in Swedish Nuclear Energy Policy." PhD dissertation, Uppsala Universitet.

Nohrstedt, Daniel. 2008. “The Politics of Crisis Policymaking: Chernobyl and Swedish Nuclear Energy Policy." The Policy Studies Journal 36 (2): 257-278.

Nohrstedt, Daniel, and Christopher M. Weible. 2010. "The Logic of Policy Change after Crisis: Proximity and Subsystem Interaction." Risk, Hazards and Crisis in Public Policy 1 (2): 1-32.

Nullmeier, Frank, and Matthias Dietz. 2012. "Überzeugungswandel-Zur Erklärung von Politikwechseln am Beispiel der Atompolitik 2010 und 2011." In Politikwechsel als Governanceproblem, eds. Jens Kersten, and Gunnar F. Schuppert. Baden-Baden: Nomos Verlagsgesellschaft, 88-113.

Pierson, Paul. 2000. "Increasing Returns, Path Dependence, and the Study of Politics." The American Political Science Review 94 (2): 251-267.

Pollack, Mark A., and Gregory C. Shaffer. 2009. When Cooperation Fails: The International Law and Politics of Genetically Modified Foods. New York: Oxford University Press.

Richardson, Jeremy. 2000. "Government, Interest Groups and Policy Change." Political
Studies 48: 1006-1025.

Sabatier, Paul A. 1998. "The Advocacy Coalition Framework: Revisions and Relevance for Europe." Journal of European Public Policy 5 (1): 98-130.

Sabatier, Paul A., and Christopher M. Weible. 2007. "The Advocacy Coalition FrameworkInnovations and Clarifications." In Theories of the Policy Process, ed. Paul A. Sabatier. Boulder, CO: Westview Press, 189-220.

Sabatier, Paul A., and Hank C. Jenkins-Smith. 1999. "The Advocacy Coalition Framework: An Assessment." In Theories of the Policy Process, ed. Paul A. Sabatier. Boulder, CO: Westview Press, 117-166.

Schlager, Edella. 2007. "A Comparison of Frameworks, Theories, and Models of Policy Processes." In Theories of the Policy Process, ed. Paul A. Sabatier. Boulder, CO: Westview Press, 293-319.

Schmidt, Vivien A., and Claudio M. Radaelli. 2004. "Policy Change and Discourse in Europe: Conceptual and Methodological Issues." West European Politics 27 (2): 183-210.

Schneider, Carsten Q., and Claudius Wagemann. 2012. Set-Theoretic Methods for the Social Sciences: A Guide to Qualitative Comparative Analysis. New York: Cambridge University Press.

Siegrist, Michael, Bernadette Sütterlin, and Carmen Keller. 2014. "Why have Some People Changed their Attitudes toward Nuclear Power after the Accident in Fukushima?" Energy Policy 69: 356-363.

Snow, David A. 2004. "Framing Processes, Ideology, and Discursive Fields." In The Blackwell Companion to Social Movements, 
eds. David A. Snow, Sarah Anne Soule, and Hanspeter Kriesi. Oxford: Blackwell, 380412.

Stefes, Christoph H. 2014. "Energiewende: Critical Junctures and Path Dependencies Since 1990." In Rapide Politikwechsel in der Bundesrepublik: Theoretischer Rahmen und empirische Befunde, ed. Friedbert W. Rüb. Baden-Baden: Nomos Verlagsgesellschaft, 47-70.

Strunz, Sebastian. 2014. "The German Energy Transition as a Regime Shift." Ecological Economics 100: 150-158.

't Hart, Paul, and Karen Tindall. 2009. "Understanding Crisis Exploitation: Leadership, Rhetoric and Framing Contests in Response to the Economic Meltdown." In Framing the Global Economic Downturn: Crisis Rhetoric and the Politics of Recessions, eds. Paul 't Hart, and Karen Tindall. Canberra: Australian National University E Press, 21-40.

The Asahi Shimbun. 2014. "Asahi Poll: 59 Percent Oppose Restart of Nuclear Reactors." https://ajw.asahi.com/article/0311disaster/fukushima/AJ201403180058 (July 26, 2015).

Valentine, Scott V., and Benjamin K. Sovacool. 2010. "The Socio-Political Economy of Nuclear Power Development in Japan and South Korea." Energy Policy 38: 79717979.

Weible, Christopher M. 2008. "Expert-Based Information and Policy Subsystems: A Review and Synthesis." The Policy Studies Journal 36 (4): 615-635.

Weible, Christopher M., Paul A. Sabatier, and Kelly McQueen. 2009. "Themes and
Variations: Taking Stock of the Advocacy Coalition Framework." The Policy Studies Journal 37 (1): 121-140.

Wittneben, Bettina B.F. 2012. "The Impact of the Fukushima Nuclear Accident on European Energy Policy." Environmental Science and Policy 15: 1-3.

Zahariadis, Nikolaos. 2007. "The Multiple Streams Framework: Structure, Limitations, Prospects." In Theories of the Policy Process, ed. Paul A. Sabatier. Boulder, CO: Westview Press, 65-92.

\section{Acknowledgements}

I wish to thank Burkard Eberlein, Maya Jegen, Achim Lang, Matthew Maguire, Emmanuelle Reuter, Volker Schneider, and Rolf Wüstenhagen for their valuable comments on earlier versions of this article. Discourse data for the case study on Japan were generously provided by Atsushi Sasai, and I am particularly grateful for that. In addition, I would like to acknowledge the very constructive suggestions of two anonymous reviewers. 